\title{
Lysosomal Dysfunction in Down Syndrome Is APP-Dependent and Mediated by APP- $\beta$ CTF (C99)
}

\author{
Ying Jiang, ${ }^{1,2}$ Yutaka Sato, ${ }^{1}$ Eunju Im, ${ }^{1,2}$ Martin Berg, ${ }^{1}$ Matteo Bordi, ${ }^{1,5}$ @Sandipkumar Darji, ${ }^{1}$ Asok Kumar, ${ }^{1}$ \\ Panaiyur S. Mohan, ${ }^{1,2}$ Urmi Bandyopadhyay, ${ }^{6}$ Antonio Diaz, ${ }^{6}$ Ana Maria Cuervo, ${ }^{6}$ and Ralph A. Nixon ${ }^{1,2,3,4}$ \\ ${ }^{1}$ Center for Dementia Research, Nathan Kline Institute for Psychiatric Research, Orangeburg, New York, 10962, Departments of ${ }^{2}$ Psychiatry, ${ }^{3}$ Cell Biology, \\ ${ }^{4}$ NYU Neuroscience Institute, New York University School of Medicine, New York, New York 10016, ${ }^{5}$ Department of Biology, University of Rome Tor \\ Vergata, Rome, Italy, and ${ }^{6}$ Department of Developmental and Molecular Biology, Albert Einstein College of Medicine, Bronx, New York, 10461
}

Lysosomal failure underlies pathogenesis of numerous congenital neurodegenerative disorders and is an early and progressive feature of Alzheimer's disease (AD) pathogenesis. Here, we report that lysosomal dysfunction in Down ayndrome (trisomy 21), a neurodevelopmental disorder and form of early onset $\mathrm{AD}$, requires the extra gene copy of amyloid precursor protein (APP) and is specifically mediated by the $\beta$ cleaved carboxy terminal fragment of APP (APP- $\beta$ CTF, C99). In primary fibroblasts from individuals with DS, lysosomal degradation of autophagic and endocytic substrates is selectively impaired, causing them to accumulate in enlarged autolysosomes/ lysosomes. Direct measurements of lysosomal $\mathrm{pH}$ uncovered a significant elevation ( 0.6 units) as a basis for slowed LC3 turnover and the inactivation of cathepsin D and other lysosomal hydrolases known to be unstable or less active when lysosomal $\mathrm{pH}$ is persistently elevated. Normalizing lysosome $\mathrm{pH}$ by delivering acidic nanoparticles to lysosomes ameliorated lysosomal deficits, whereas RNA sequencing analysis excluded a transcriptional contribution to hydrolase declines. Cortical neurons cultured from the Ts2 mouse model of DS exhibited lysosomal deficits similar to those in DS cells. Lowering APP expression with siRNA or BACE1 inhibition reversed cathepsin deficits in both fibroblasts and neurons. Deleting one Bace1 allele from adult Ts2 mice had similar rescue effects in vivo. The modest elevation of endogenous APP- $\beta$ CTF needed to disrupt lysosomal function in DS is relevant to sporadic AD where APP- $\beta$ CTF, but not APP, is also elevated. Our results extend evidence that impaired lysosomal acidification drives progressive lysosomal failure in multiple forms of AD.

Key words: AD; APP- $\beta$ CTF; cathepsin D; Down syndrome; lysosomal pH; lysosome

Significance Statement

Down syndrome (trisomy 21) (DS) is a neurodevelopmental disorder invariably leading to early-onset Alzheimer's disease (AD). We showed in cells from DS individuals and neurons of DS models that one extra copy of a normal amyloid precursor protein $(A P P)$ gene impairs lysosomal acidification, thereby depressing lysosomal hydrolytic activities and turnover of autophagic and endocytic substrates, processes vital to neuronal survival. These deficits, which were reversible by correcting lysosomal $\mathrm{pH}$, are mediated by elevated levels of endogenous $\beta$-cleaved carboxy-terminal fragment of APP (APP- $\beta$ CTF). Notably, similar endosomal-lysosomal pathobiology emerges early in sporadic AD, where neuronal APP- $\beta$ CTF is also elevated, underscoring its importance as a therapeutic target and underscoring the functional and pathogenic interrelationships between the endosomallysosomal pathway and genes causing AD.

\section{Introduction}

Lysosome-mediated degradative systems, including the endosomal-lysosomal pathway and autophagy, are especially vital to

\section{Received March 12, 2019; revised April 19, 2019; accepted April 24, 2019.}

Author contributions: Y.J. and R.A.N. designed research; Y.J., Y.S., E.I., M. Berg, M. Bordi, A.K., P.S.M., U.B., and A.D. performed research; Y.J. contributed unpublished reagents/analytic tools; Y.J., Y.S., E.I., S.D., and A.M.C. analyzed data; Y.J. wrote the first draft of the paper; Y.J., E.I., A.M.C., and R.A.N. edited the paper; Y.J. and R.A.N. wrote the paper.

This work was supported by the National Institute on Aging P01 AG017617 to R.A.N.

The authors declare no competing financial interests. the survival of neurons based on the dozens of congenital primary lysosomal storage disorders that are characterized by their severe neurodevelopmental and neurodegenerative phenotypes (Nixon, 2017; Lie and Nixon, 2019). Lysosomal dysfunction is also increasingly recognized as a pathogenic factor in aging-related neurodegenerative diseases and is particularly

Correspondence should be addressed to Ralph A. Nixon at ralph.nixon@nki.rfmh.org.

https://doi.org/10.1523/JNEUROSCI.0578-19.2019

Copyright $\odot 2019$ the authors 
strongly implicated in Alzheimer's disease (AD), where genetic (Bordi et al., 2016; Nixon, 2017; Lie and Nixon, 2019), environmental (Gamba et al., 2015; Giudetti et al., 2016; Pal et al., 2016; Zhang et al., 2017), and aging factors (Nixon et al., 2008) converge to yield early and progressive lysosomal disruption that compromises diverse neural functions and is a likely neuronal trigger for cell death (Nixon and Cataldo, 1993; Nixon and Yang, 2012).

Endosomal-lysosomal pathway deficits characterized by upregulated endocytosis, aberrant endosome trafficking and signaling, and progressive lysosomal dysfunction are a signature neuropathological pattern emerging at the earliest stages of sporadic AD. Notably, this pattern begins perinatally in Down syndrome (DS) (Cataldo et al., 1997, 2000), a disorder in which an early onset form of AD invariably develops due mainly to a third copy of APP present on trisomic chromosome 21 (Korbel et al., 2009; Doran et al., 2017; Colacurcio et al., 2018). Beyond their roles in sorting and recycling of internalized cargoes and cell signaling, endosomes are major sites of APP processing by $\beta$ site cleaving enzyme 1 (BACE1), generating $\beta$ cleaved carboxy terminal fragment of APP ( $\beta$ CTF) (Vassar et al., 1999), which mediates AD-related endosome dysfunction and diverse neuronal deficits (Nixon, 2017). Notably, BACE1 activity and APP- $\beta$ CTF levels are elevated in AD brain in the absence of detectable APP elevation (Holsinger et al., 2002; Pera et al., 2013; Kim et al., 2016). Early neuronal accumulation of APP- $\beta$ CTF in AD mouse models is linked to neuronal hyperactivity (Goutagny et al., 2013), A $\beta$ independent LTP deficits and cognitive impairment (Simón et al., 2009; Tamayev et al., 2011; Lauritzen et al., 2012; MondragónRodríguez et al., 2014), and cholinergic neurodegeneration (Jiang et al., 2016). Intraneuronal accumulation of APP- $\beta$ CTF is reported to be both a cause and effect of autophagy-lysosomal pathology and APP- $\beta$ CTF aggregate accumulation in 3xTg AD mice (APPswe, $P 1_{\mathrm{M} 146 \mathrm{~V}}$, and $\mathrm{Tau}_{\mathrm{P} 301 \mathrm{~L}}$ ) (Lauritzen et al., 2012, 2016) and in several FAD-mutated APP overexpression models in mice (Yang et al., 2014; Kaur et al., 2017; Bourgeois et al., 2018), and in the neurons generated from induced pluripotent stem cells derived from individuals with PSEN1 as well as APP mutations (Hung and Livesey, 2018).

In the present study, we investigated the influence of increased APP gene dosage, and specifically the role of APP- $\beta$ CTF in causing lysosomal dysfunction in primary fibroblasts from individuals with DS and in neurons from the Ts2 mouse model of DS in primary cultures or in adult brain in vivo. Importantly, primary DS fibroblasts represent authentic human DS genetically unmodified, in contrast to previously used genetically modified models of AD engineered by the transgenic overexpression of APP carrying FAD mutations together in some cases with other mutated AD-related human genes. The findings of our study reveal an early disruption of lysosomal degradative function driven by impaired luminal acidification of lysosomes and specifically caused by a modest elevation of APP- $\beta$ CTF. Thus, lysosomal deficits, like previously described anomalies of endosomes (Jiang et al., 2010) and exosomes (Perez-Gonzalez et al., 2012; Gauthier et al., 2017), are interrelated pathobiology at the earliest phase of AD linked to a common proximal genetic factor. The detection of functional lysosomal abnormalities preceding the flagrant lysosomal pathology and accumulation of lysosomal content imply a proximal link to the gene most strongly implicated in $\mathrm{AD}$. The findings reinforce the concept that the causal effects of App in driving $\mathrm{AD}$ depends on a range of metabolites generated in the Endosomal-Lysosomal system (ELS), including APP- $\beta C T F$, which are capable of disrupting ELS function.

\section{Materials and Methods}

Antibodies, reagents, and plasmids. Antiserum to RAB7 (ab50533) was from Abcam, EEA1 (610456) from BD Biosciences, and LC3 (NB1002220) from Novus; antibodies to total p-70 (9202) and pThr389-p70 (9205) were from Cell Signaling Technology, Lamp2 (H4B4) from Developmental Studies Hybridoma Bank, cathepsin B (CTSB, GT15047) from Neuromics (Wolfe et al., 2013), cathepsin D (CTSD) from Scripps Institute (90236), antibodies against APP, APP-CTFs (C1/6.1, 6E10, $\mathrm{N} 25$ ), and CTSD (CD1.1) have been described previously (Mathews et al., 2002), actin (A2066) and GAPDH (G9545) from Sigma-Aldrich/ Millipore. Inhibitors used were AZD8055 (Selleck Chemicals), leupeptin and Pepstatin A (Peptide Institute), $\gamma$-secretase inhibitor (L-685,458; Tocris Bioscience), and $\beta$-secretase inhibitor IV (565788, Calbiochem).

mRFP-eGFP-LC3 DNA construct was kindly provided by Dr. Tamotsu Yoshimori (Osaka University) (Kimura et al., 2007; Lee et al., 2010). $\beta$ CTF-mCherry was generated from pmCherry-N1 vector (Clontech) and $\beta$ CTF-GFP construct (Haass and Selkoe, 1993).

Cell culture and transfection. Human foreskin fibroblasts from DS patients and diploid age-matched controls $(2 \mathrm{~N})$ were purchased from the Coriell Cell Repositories (AG07096, AG04823, GM04617, GM08680, AG07095, AG06922, GM08429, GM5381) and maintained according to the distributor's protocols (http://ccr.coriell.org/). Throughout this study, fibroblasts were used below passage number 15 to keep the original character and morphology. Primary cortical neuronal cultures were prepared as described previously (Boland et al., 2008). Genotyping to distinguish $2 \mathrm{~N}$ and Ts2 mice was performed as described previously (Duchon et al., 2011). Mice used in this study were maintained according to Institutional Animal Care and Use Committee guidelines and protocols for animal experimentation at Nathan S. Kline Institute.

siRNA against human APP and negative control DsiRNA was purchased from Integrated DNA Technologies and used as previously described (Jiang et al., 2010). siPORT Amine (AM4503, Thermo Fisher Scientific) was used for both plasmid and siRNA transfection in fibroblasts and cells were live imaged, fixed for immunocytochemistry (ICC), or collected for protein analysis $3 \mathrm{~d}$ after siRNA transfection (Jiang et al., 2010). siRNA for mouse APP (E-043246-00-0010) and negative control (D-001910-10-20) for neurons were purchased from Thermo Fisher Scientific. For delivery of siRNA into neuronal culture, cells at 4 DIV were incubated with Accell siRNA for the mouse APP gene or negative control with Accell siRNA Delivery Media (Thermo Fisher Scientific Scientific) for $3 \mathrm{~d}$.

CTSD, CTSB, acid phosphatase (ACP2), and hexosaminidase (HEXA) enzyme activity assay. In vitro CTSD and CTSB enzyme assays were conducted, and specific activities were calculated according to our previous reports (Marks and Berg, 1987; Lee et al., 2010; Wolfe et al., 2013), whereas in situ CTSD activity was determined by live imaging of the cell incubated with BODIPY FL-Pepstatin A for 30 min (P12271, Thermo Fisher Scientific) (Lee et al., 2010). CTSB in situ activity was measured using the Magic Red Cathepsin-B Assay Kit (ImmunoChemistry Technologies) per the manufacturer's protocol (Wolfe et al., 2013). ACP2 in vitro enzyme activity was determined using DiFMUP (Invitrogen, D6567) and a method modified from a previous publication (Gee et al., 1999). HEXA in vitro enzyme activity was determined as previously reported (Wendeler and Sandhoff, 2009).

Acidic nanoparticle treatment. Poly-(DL-lactide-co-glycolide) Resomer 503H (719870)-based nanoparticle (NP3) was obtained from Dr. Baltazar and used as previously described (Baltazar et al., 2012). 2N and DS fibroblasts were incubated with MEM culture media containing $1 \mathrm{mg} / \mathrm{ml}$ NP3 for $24 \mathrm{~h}$ before further lysosomal functional analysis.

Immunocytochemistry. In general, fibroblasts and primary cortical neurons were fixed with $4 \%$ PFA/PBS for $20 \mathrm{~min}$ at room temperature, blocked with $5 \%$ horse serum for $1 \mathrm{~h}$, incubated with various primary antibodies overnight at $4{ }^{\circ} \mathrm{C}$, and followed by fluorescencetagged secondary antibodies (1:1000, Thermo Fisher Scientific) (Jiang et al., 2010). An LSM880 confocal microscope (Carl Zeiss) was used to collect images, which were then quantified with ImageJ (https://imagej.nih.gov/ij/). Colocalization was determined using the JACoP Plug-In on ImageJ software. 
Lysosome and late endosome size measurement. The sizes of lysosomes and late endosomes were determined according to a previous publication (Bright et al., 2005). Briefly, fibroblasts were incubated with $0.05 \mathrm{mg} / \mathrm{ml}$ lysine-fixable dextran-AlexaFluor-546 or AlexaFluor-647 for $4 \mathrm{~h}$ pulse at $37^{\circ} \mathrm{C}$ followed by a $20 \mathrm{~h}$ chase in regular cell culture media before fixation for lysosomes, whereas a $10 \mathrm{~min}$ pulse with $0.25 \mathrm{mg} / \mathrm{ml}$ lysine-fixable dextran-Alexa- 488 followed by $10 \mathrm{~min}$ chase was used for late-endosome size determination. Cell images were taken by an LSM880 confocal microscope (Carl Zeiss) and puncta quantified with ImageJ.

Lysosome isolation and $\mathrm{pH}$ measurement. Lysosomes were isolated with dextran-conjugated magnetite (Liquid Research), followed by Western blot analysis as previously described (Lee et al., 2015), whereas lysosomal $\mathrm{pH}$ was measured by LysoSensor Yellow/Blue dextran, as previously described (Wolfe et al., 2013).

Intracellular protein degradation measurements. Fibroblasts were labeled with $\left[{ }^{3} \mathrm{H}\right]$-leucine $(2 \mu \mathrm{Ci} / \mathrm{ml})$ for $2 \mathrm{~d}$ at $37^{\circ} \mathrm{C}$ to increase labeling of long-lived proteins. After extensive washing, cells were maintained in a complete medium or serum-free medium with excess unlabeled leucine to avoid reuptake of labeled leucine into newly synthesized proteins. Aliquots taken from the media at the indicated times were subjected to TCA precipitation, and the radioactivity detectable in the acid-soluble fraction (peptides and amino acids) and the acid-precipitated fraction (proteins) was detected in a liquid scintillation $\beta$-counter. A combination of $20 \mathrm{~mm} \mathrm{NH}_{4} \mathrm{Cl}$ and $100 \mu \mathrm{m}$ leupeptin (NL) was used to block lysosomal protein degradation. The rates of total protein degradation at the indicated times were calculated as a percentage of total radiolabeled protein degraded to soluble amino acids as described previously (Auteri et al., 1983; Cuervo et al., 2004).

Electron microscopy (EM). Fluid phase uptake study was determined by using HRP (Type II, Sigma-Aldrich) according to an earlier study (Cataldo et al., 2008). The fibroblasts were then washed 3 times with 0.1 M sodium cacodylate buffer, postfixed in $1 \%$ osmium tetroxide, and progressively dehydrated in a graded series of ethanol (50\%-100\%) followed by embedding in Epon (Electron Microscopy Sciences) for at least $3 \mathrm{~d}$ at room temperature. Epon-embedded blocks were sectioned and placed on copper grids for structural analysis. EM images in each condition were randomly selected and captured, and the number of HRPpositive vesicles was manually counted (Lee et al., 2010).

RNA sequencing (RNA-Seq). RNA was extracted from human fibroblasts using RNeasy Micro Kit (QIAGEN) according to the manufacturer's specifications and digested with DNase I (Sigma-Aldrich). RNA quantity and quality were determined with a Nanodrop 1000 spectrophotometer and 2100 Bioanalyzer (Agilent Technologies). Three biological replicas were produced per each cell line; $500 \mathrm{ng}$ of total RNA was prepared using TruSeq RNA Sample prep kit V2 (Illumina) following the manufacturer's protocol. mRNA-Seq libraries were prepared and sequencing done at New York Genome Center (https://www.nygenome. org) using HiSeq 2000 (Illumina) (M.B., manuscript submitted). Quality of libraries was assessed using a 2100 Bioanalyzer. We obtained on average 52 million $50 \mathrm{bp}$ single-end reads and $50 \mathrm{bp}$ paired-end reads per sample that were separately aligned to the human genome (hg19, GRCh37) downloaded from University of California at Santa Cruz. STAR software (version 2.3.1z) was used for processing reads with the default parameters. The resulting aligned datasets in bam format was assembled into transcripts using HTSeq (version 0.6.1p2).

RNA-Seq data analysis. The Differential Gene Expression analysis on samples treated with siNC or siAPP was performed in R software using EdgeR (Robinson et al., 2010) and Limma (Ritchie et al., 2015) packages from R/Bioconductor. The genes with read counts per million (cpm) of $\geq 0.3$, equivalent to at least $\sim 10$ raw read counts, in at least one group were considered for downstream analysis. A separate Differential Gene Expression analysis was also performed to compare trisomic and disomic transcriptomic profiles, in conjunction with age-matched unrelated disomic and trisomic human fibroblasts mRNA-Seq samples available under Gene Expression Omnibus accession GSE55504 and GSE79842 (Letourneau et al., 2014; Sullivan et al., 2016) to increase the degree of freedom and power of statistical analysis. The final count constitutes 10 DS samples and $112 \mathrm{~N}$ samples. Using Limma's duplicateCorrelation functionality, the correlation between biological replicates from the same subjects was estimated, and this intersubject correlation was fitted into the linear model to avoid an overfit and inflation of $p$ values, thus reducing the false positives. Expression values were finally normalized and reported as $\log$ base 10 of transcript per million as prescribed (Mortazavi et al., 2008). The raw and processed data were deposited to Gene Expression Omnibus under accession number GSE127880.

Statistical analysis. All quantitative data were subjected to two-tailed unpaired Student's $t$ test for single comparison, or one-way ANOVA analysis for multiple comparisons with post hoc Tukey's analysis using Prism 6 (GraphPad). Most data are represented as box-and-whisker plots, also showing group means as crosses (in the figures). For data involving $<6$ repeats, mean \pm SEM are represented in bar graphs with individual data points.

\section{Results}

\section{Decreased lysosomal turnover of autophagic protein substrates in DS fibroblasts}

We assessed lysosomal turnover in $2 \mathrm{~N}$ and DS fibroblasts by measuring intracellular proteolysis of radiolabeled long-lived proteins in cells grown in serum-replete medium, a condition under which autophagy activity is low (basal autophagy); and in serum starved cells, a condition under which autophagy and lysosomaldependent proteolysis are strongly induced (inducible lysosomal degradation) (Komatsu et al., 2005). 2N and DS fibroblasts labeled with $\left[{ }^{3} \mathrm{H}\right]$-leucine for $48 \mathrm{~h}$ were then chased for 6,12 , and $20 \mathrm{~h}$, at which time points the percentage release of TCA-soluble labeled amino acid was measured (Fig. $1 A-D$ ). Rates of degradation of long-lived proteins, both in the presence (Fig. $1 A ; t_{(18)}=$ $2.586, p=0.0186$ for $12 \mathrm{~h}$ time point, $t_{(18)}=3.284, p=0.0041$ for 20 h time point; unpaired $t$ test) and absence of serum (Fig. $1 C$; $t_{(18)}=2.440, p=0.0253$ for $12 \mathrm{~h}$ time point; $t_{(18)}=2.907, p=$ 0.0094 for $20 \mathrm{~h}$ time point; unpaired $t$ test), were significantly reduced in DS fibroblasts compared with $2 \mathrm{~N}$ cells. Treatment of the cells with a combination of lysosomal proteolysis inhibitors, $\mathrm{NH}_{4} \mathrm{Cl}(20 \mathrm{~mm})$ and leupeptin $(100 \mu \mathrm{M})(\mathrm{NL})$, eliminated proteolytic rate differences between $2 \mathrm{~N}$ and DS (Fig. $1 B$; $t_{(18)}=0.027, p=0.978$ for $12 \mathrm{~h}$ time point; $t_{(18)}=0.405, p=$ 0.689 for $20 \mathrm{~h}$ time point; unpaired $t$ test; Fig. $1 D ; t_{(18)}=0.837$, $p=0.414$ for $12 \mathrm{~h}$ time point; $t_{(18)}=0.173, p=0.865$ for $20 \mathrm{~h}$ time point; unpaired $t$ test), demonstrating that the proteolysis deficit in DS fibroblasts is a result of selectively impaired lysosomal degradation.

Consistent with effects of serum starvation, inducing autophagy and selectively blocking mammalian target of rapamycin (mTOR: TORC1 and TORC2) with the specific inhibitor AZD8055 (AZD) (Chresta et al., 2010), markedly lowered phosphorylation of the mTOR substrate-p70 (Pullen et al., 1998) (Fig. $1 E)$. Although LC3-II levels in untreated $2 \mathrm{~N}$ and DS cells were similar, AZD treatment for $2 \mathrm{~h}$ elevated LC3-II in DS cells to levels significantly higher than those in $2 \mathrm{~N}$ fibroblasts (Fig. $1 E, F ; t_{(10)}=$ $6.570, p<0.0001$; unpaired $t$ test). The addition of protease inhibitors leupeptin and pepstatin A (LP) (Ivy et al., 1989; Chen et al., 2000) to AZD-treated DS and $2 \mathrm{~N}$ cells equalized LC3-II levels in the two cell lines (Fig. $1 E, F ; t_{(10)}=0.717, p=0.450$; unpaired $t$ test), suggesting that the rates of autophagosome (AP) formation were similar when autophagy is strongly induced and that, in the absence of protease inhibitors, the higher LC3-II levels in AZD-treated DS fibroblasts than in treated $2 \mathrm{~N}$ cells were due to impaired lysosomal degradation. Consistent with this evidence of less efficient lysosomal proteolysis in DS fibroblasts, sizes of lysosomes quantified after dextran-AlexaFluor-546 uptake, were larger in untreated DS cells than in $2 \mathrm{~N}$ cells (Fig. $1 G, H$ ), and, as expected, AZD treatment elevated lysosomal size in both $2 \mathrm{~N}$ and DS fibroblasts (Fig. $1 G, H ; F_{(3,3641)}=36.83, p<0.0001$; one-way 
A

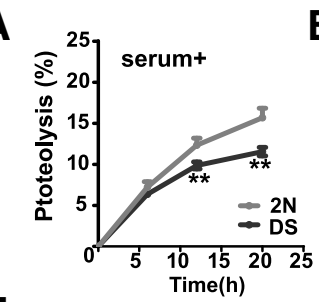

E

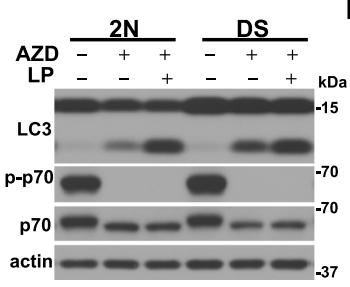

I

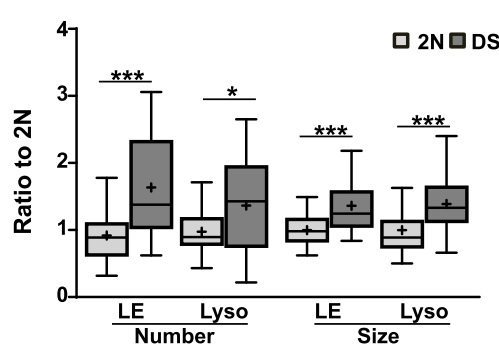

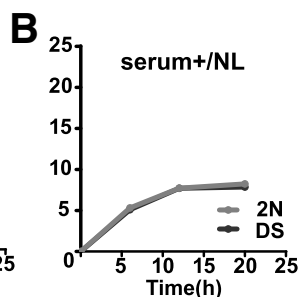

$\mathbf{F}$

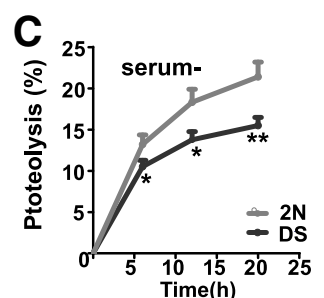

$\mathrm{G}_{2 \mathrm{~N}}$
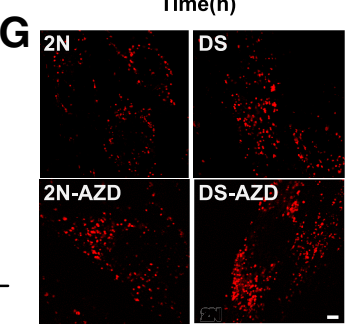

$\mathrm{J}$

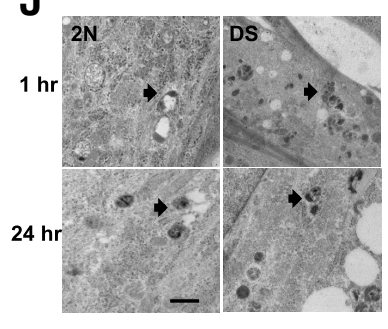


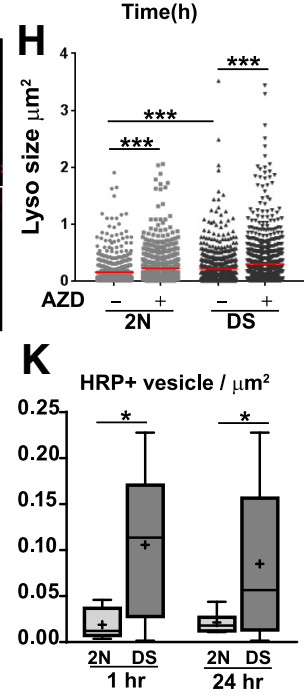

Figure 1. Decreased lysosomal turnover of autophagic protein substrates in DS fibroblasts. $A-D$, Fibroblasts from 3 different DS patients and age-matched control were labeled for $2 \mathrm{~d}$ with [ ${ }^{3} \mathrm{H}$ ] leucine. After extensive washing, cells were plated in complete medium $(\boldsymbol{A}, \boldsymbol{B})$ or in serum-depleted media $(\boldsymbol{C}, \boldsymbol{D})$; and where indicated, $(\boldsymbol{B}, \boldsymbol{D}) 20 \mathrm{~mm} \mathrm{NH}{ }_{4} \mathrm{Cl} / 100 \mu \mathrm{m}$ leupeptin $(\mathrm{NL})$ was added into the incubation medium. The rate of total protein degradation at the indicated times was calculated as the percentage of total radiolabeled protein transformed in soluble amino acids and small peptides at each time. Values are the mean \pm SEM ( $n=10$ replicates). $E$, Western blotting of autophagy-related proteins in $2 \mathrm{~N}$ and DS fibroblasts treated with vehicle or AZD ( $0.5 \mu \mathrm{m}$ for $2 \mathrm{~h}$ ) and with or without leupeptin and pepstatin A (LP, $10 \mu \mathrm{m}$ for $24 \mathrm{~h}$ ), with actin as an internal control, and $(\boldsymbol{F})$ quantification of LC3-II protein levels normalized with actin in $2 \mathrm{~N}$ and DS fibroblasts ( $n=$ 6 replicates). $\mathbf{G}$, Representative confocal microscopic images and $(\boldsymbol{H})$ the size quantification of lysosome identified by dextran-AlexaFluor-546 uptake (4 h pulse and $20 \mathrm{~h}$ chase) in $2 \mathrm{~N}$ and DS fibroblasts with or without AZD treatment shown as scatter plot ( $n \geq 52$ lysosomes). Red lines indicate mean values. $I$, Quantifications of size and number of endosomes and lysosomes in $2 \mathrm{~N}$ and DS fibroblasts ( $n \geq 30$ cells). J, Representative EM images of HRP uptake in $2 \mathrm{~N}$ and DS fibroblasts and $(\boldsymbol{K})$ the quantification of HRP-positive lysosomes at 1 and $24 \mathrm{~h}$ uptake time point ( $n \geq 9$ field). Arrows indicate HRP-positive vesicles. + sign indicates mean in Bar and Whiskers plots. n.S., not significant, ${ }^{*} p \leq 0.05,{ }^{* *} p \leq 0.01,{ }^{* * *} p \leq 0.005$. Scale bar, $5 \mu$ m.

ANOVA). Greater numbers and sizes of lysosomes in DS fibroblasts were also seen after long pulse-chase ( $4 \mathrm{~h}$ pulse and $20 \mathrm{~h}$ chase) of dextran-AlexaFluor-546, concurrent with an enlargement of endosomes revealed by a short pulse-chase (10 min-10 min) of dextran-AlexaFluor-488 (Fig. $1 I ; t_{(56)}=4.713, p<$ 0.0001 for LE number; $t_{(43)}=2.562, p=0.014$ for Lyso number; $t_{(56)}=4.521, p<0.0001$ for LE size; $t_{(43)}=2.562, p=0.0004$ for Lyso size; unpaired $t$ test). EM images taken $24 \mathrm{~h}$ after endocytic uptake of HRP revealed greater accumulation of HRP in lysosomes of DS cells than in $2 \mathrm{~N}$ cells (Fig. $1 \mathrm{~J}, K ; t_{(16)}=2.961, p=$ 0.011 for $1 \mathrm{~h} ; t_{(16)}=2.400, p=0.0289$ for $24 \mathrm{~h}$; unpaired $t$ test), showing that endocytic cargoes reaching lysosomes in DS cells persisted there longer. Furthermore, DS cells also showed reduced capacity to eliminate damaged mitochondria in response to mitochondrial depolarization by carbonyl cyanide m-chlorophenyl hydrazone (Bordi et al., manuscript submitted).

\section{Lysosomal acidification deficiency in DS fibroblasts}

Defective lysosomal acidification has been shown to be a basis for lysosomal dysfunction in an expanding number of neurodegenerative diseases and, in some cases, constitutes the primary pathogenic mechanism of disease (Majumdar et al., 2007; Lee et al., 2010; Dehay et al., 2013; Wolfe et al., 2013; Colacurcio and Nixon, 2016). To directly measure lysosomal $\mathrm{pH}$ in $2 \mathrm{~N}$ and DS fibroblasts, we used dextran-conjugated Lysosensor Yellow/Blue, a ratiometric dye targeted to lysosomes (Diwu et al., 1999; Lee et al., 2010; Wolfe et al., 2013). Lysosomal pH was significantly higher in DS fibroblasts than in $2 \mathrm{~N}$ cells $(\mathrm{pH}=5.03 \pm 0.08$ vs $4.66 \pm 0.06, t_{(92)}=8.414, p<0.0001$; unpaired $t$ test). We confirmed the lysosomal acidification deficit in DS fibroblasts by expressing in the cell lines a tandem fluorescent-tagged LC3 (mRFP-eGFP-LC3) probe, which has been used to monitor autophagic flux (Kimura et al., 2007; Lee et al., 2010, 2019; Zhou et al., 2012). We combined transfection of this construct with the uptake and lysosomal delivery of dextran-AlexaFluor-647 to fluorescently mark lysosomes. Fusion of APs with normally functioning lysosomes rapidly lowers the $\mathrm{pH}$ within resulting autolysosomes (ALs) (Lee et al., 2019). In this triple-fluorescence labeling paradigm (Fig. $2 A$ ), AL puncta are colored purple with fluorescence solely from the red and blue channels due to the quenching of GFP at the lowered pH (Lee et al., 2019). By contrast, when AL acidification is impaired after AP-lysosome fusion, the resulting AL puncta fluoresce white, reflecting the contribution of unquenched GFP to the net fluorescence of mRFP and AlexaFluor-647 (Lee et al., 2019). The hue angle and saturation for each puncta, reflecting percentage contributions of each of the three fluorescence labels, was then determined accordingly (Lee et al., 2019), enabling us to objectively identify and quantify lysosomes, APs, and ALs that are acidified, incompletely acidified, or unacidified, (Lee et al., 2019). Consistent with our results from direct measurements of lysosomal $\mathrm{pH}$, DS fibroblasts at baseline had more than an eightfold higher percentage of poorly acidified ALs than detected in $2 \mathrm{~N}$ fibroblasts $(9.24 \pm$ 

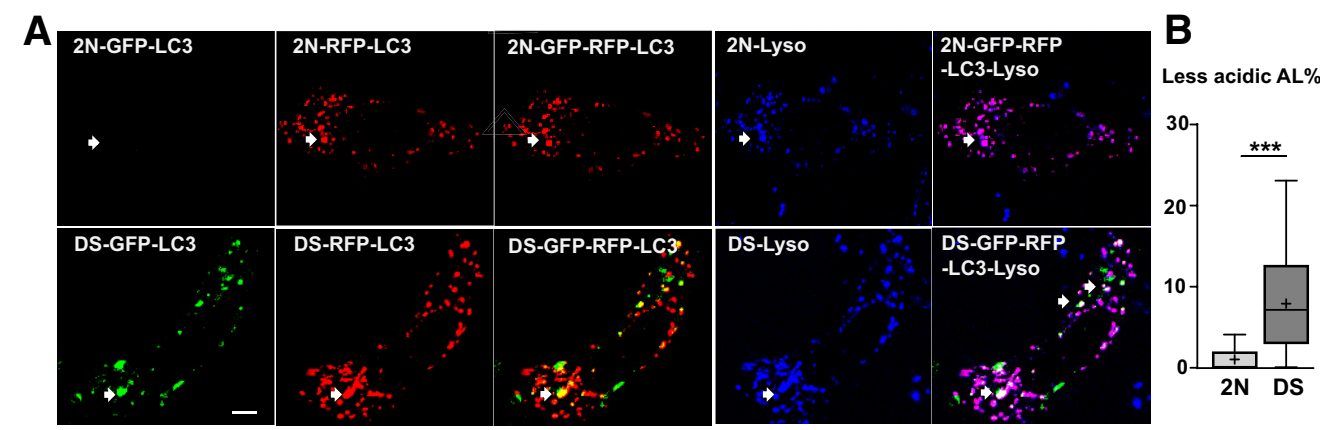

Figure 2. Lysosomal acidification deficiency in DS fibroblasts. $A$, Representative confocal microscopic images of $2 \mathrm{~N}$ and DS fibroblasts transfected with $\mathrm{mRFP-eGFP-LC3} \mathrm{for} 48 \mathrm{~h}$ and dextranAlexaFluor-647 uptake as lysosome marker and ( $\boldsymbol{B}$ ) less acidic ALs as a percentage of total ALs ( $n \geq 31$ cells). Arrows indicate a less acidic AL. + sign indicates mean in Bar and Whiskers plot. ${ }^{* * *} p \leq$ 0.005. Scale bar, $5 \mu \mathrm{m}$.
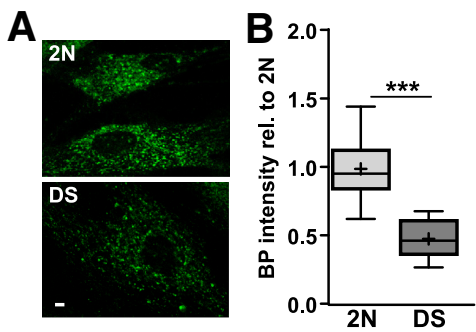

$\mathbf{E}$

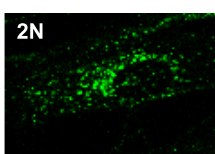

DS
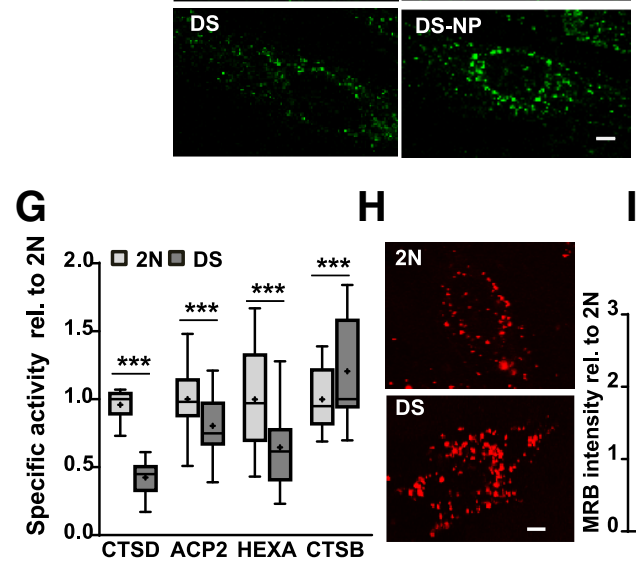

I

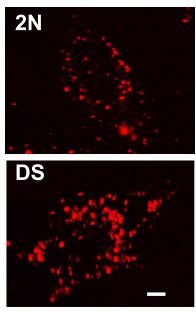

C

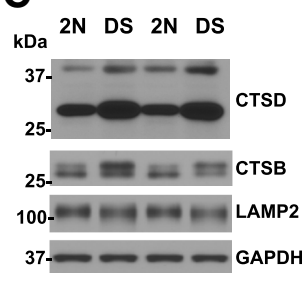

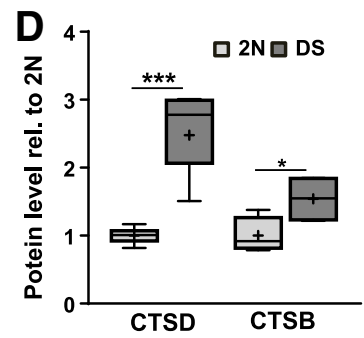

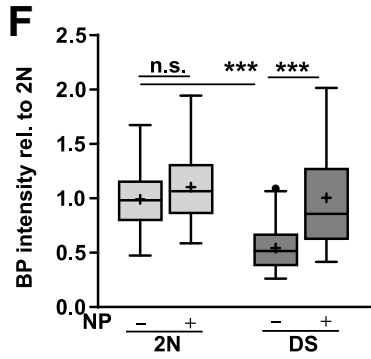



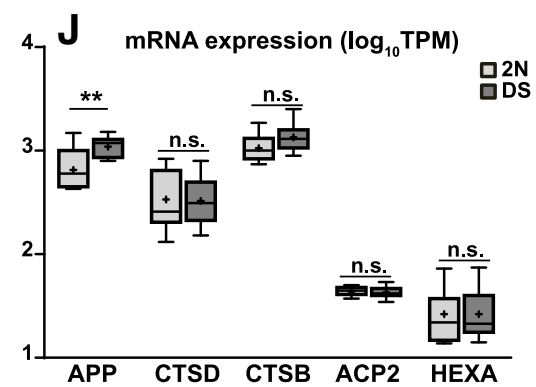

Figure 3. Altered lysosomal enzymatic activity in DS fibroblasts. $A$, Representative confocal microscopic images and (B) the quantification of BODIPY FL-Pepstatin A (BP) labeling in $2 \mathrm{~N}$ and DS fibroblasts ( $n \geq 42$ cells). C, Representative Western blotting of CTSD ( $n=9$ replicates) and CTSB ( $n=4$ replicates) from total extracts of $2 N$ and DS fibroblasts, and their quantification (D). $\boldsymbol{E}$, Representative images of BODIPY FL-Pepstatin A staining and $(\boldsymbol{F})$ the quantification of fluorescence intensity in $2 \mathrm{~N}$ and DS fibroblasts treated with nanoparticles for $24 \mathrm{~h}$ ( $n \geq 74$ cells). $\boldsymbol{G}$, Specific activity of CTSD, ACP2, HEXA, and (TSB measured by their corresponding in vitro activity assay ( $n \geq 6$ replicates). $\boldsymbol{H}$, Representative confocal microscopic images and $(\boldsymbol{I})$ the quantification of Magic Red CatB (MRB) labeling in $2 \mathrm{~N}$ and DS fibroblasts ( $n \geq 131$ cells). J, mRNA expression level of APP, and lysosomal enzymes from RNA-Seq analysis of $2 \mathrm{~N}$ and DS fibroblasts ( $n \geq 10$ replicates). + sign indicates mean in Bar and Whiskers plots. n.s., not significant, ${ }^{*} p \leq 0.05,{ }^{* *} p \leq 0.01,{ }^{* * *} p \leq 0.005$. Scale bar, $5 \mu \mathrm{m}$.

$1.23 \%$ vs $1.13 \pm 0.41 \%$ ) relative to the total AL population (Fig. $2 A, B ; t_{(63)}=5.987, p<0.0001$; unpaired $t$ test).

\section{Altered lysosomal enzymatic activity in DS fibroblasts}

We next investigated the possible impact of impaired acidification on activity of lysosomal hydrolases. We first assessed the level of activation of CTSD in lysosomes in situ using BODIPY FLPepstatin A, an affinity reagent that binds only to the enzymatically form of CTSD (Chen et al., 2000; Lee et al., 2010). The intensity of BODIPY FL (BP) fluorescence after cells were incubated with BODIPY FL-Pepstatin A for 30 min revealed a $45 \%$ reduction in the level of CSTD activity in the lysosomes of intact DS fibroblasts compared with that in $2 \mathrm{~N}$ control cells (Fig. $3 A, B$; $t_{(85)}=12.14, p<0.0001$; unpaired $t$ test). Notably, despite this markedly lowered lysosomal CTSD activation in DS cells, quantitative immunoblot analysis showed that maturation of CTSD was not impaired in DS fibroblasts, which had 2.5-fold more mature form of $32 \mathrm{kDa}$ CTSD protein than $2 \mathrm{~N}$ cells (Fig. 3C,D; $t_{(16)}=7.939, p<0.0001$; unpaired $t$ test). We confirmed this evidence for CTSD inactivation in DS by measuring CTSD specific activity in vitro (units of enzyme activity assayed at optimal $\mathrm{pH}$ per micrograms of CTSD protein), which showed that the 
A
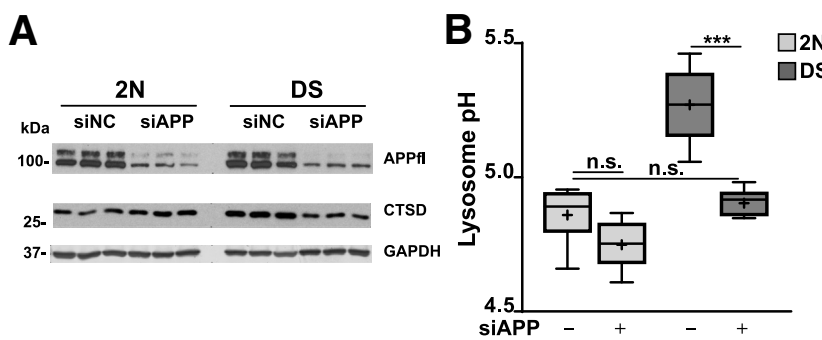

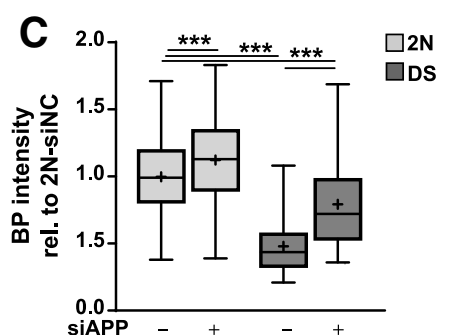

E

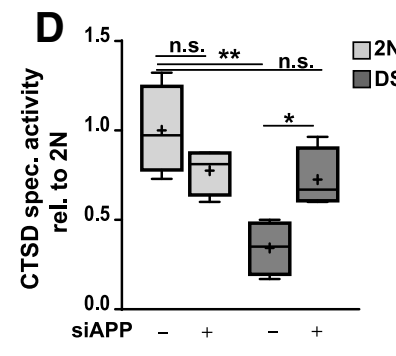

$\mathbf{F}$

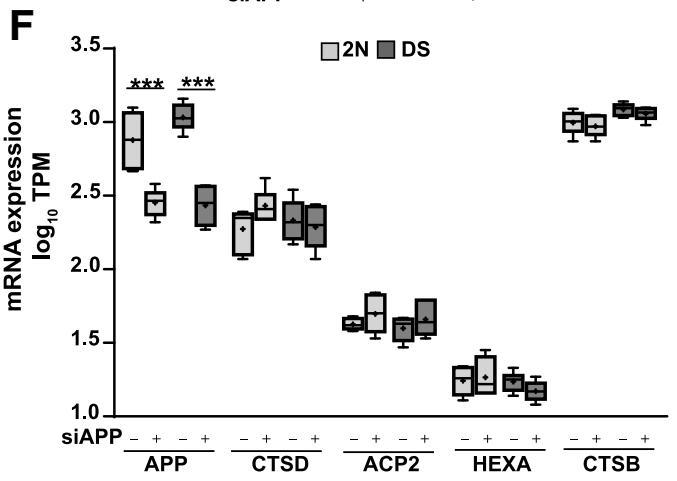

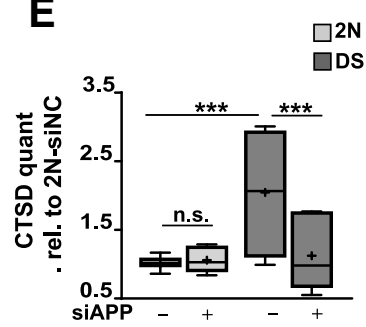

G

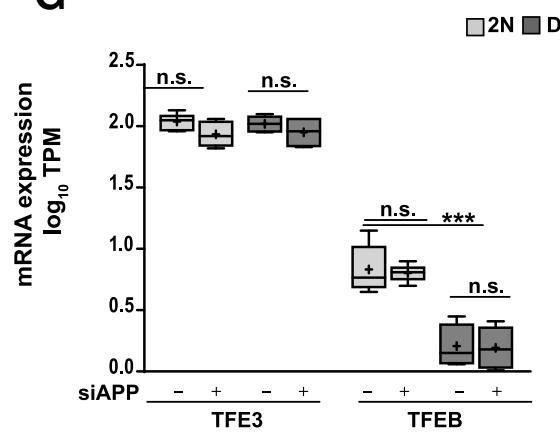

Figure 4. Regulation of (TSD activity in $2 \mathrm{~N}$ and DS fibroblasts by downregulation of APP. $A$, Representative Western blot of $2 \mathrm{~N}$ and DS fibroblast after treatment with siRNA for either negative control (siNC) or for APP (siAPP) for $72 \mathrm{~h}$ ( $n=3$ replicates). B, Lysosome $\mathrm{pH}$ of $2 \mathrm{~N}$ and DS fibroblasts treated with siNC or siAPP for $72 \mathrm{~h}$ ( $n \geq 9$ replicates) determined by LysoSensor Yellow/Blue dextran. C, Quantitation of BODIPY FL-Pepstatin A fluorescence intensity in 2N and DS fibroblasts treated with siNC or siAPP ( $n \geq 200$ cells). D, Lysosomal CTSD specific activity of 2N and DS cells treated with siNC or siAPP for 72 h. E, Quantitation of (TSD protein levels after siNC and siAPP treatment, and GAPDH as internal control. $\boldsymbol{F}$, mRNA level of APP, and lysosomal enzymes and (G) TFE3 and TFEB in $2 \mathrm{~N}$ and DS fibroblasts treated with siNC or siAPP for $72 \mathrm{~h}$ ( $n=6$ replicates). + sign indicates mean in Bar and Whiskers plots. n.s., not significant, ${ }^{*} p \leq 0.05,{ }^{* *} p \leq 0.01,{ }^{* * *} p \leq 0.005$.

specific activity of CSTD in DS fibroblasts was less than half that in $2 \mathrm{~N}$ cells (Fig. $3 G$; $t_{(15)}=8.998, p<0.0001$; unpaired $t$ test).

To investigate whether or not the lysosomal acidification deficits are responsible for CSTD inactivation in DS lysosomes, we targeted acidic poly-(DL-lactide-co-glycolide)-based nanoparticles (NP3) to lysosomes, which has previously been shown to restore normal lysosomal acidity and lysosomal function in several pathological states (Baltazar et al., 2012; Bourdenx et al., 2016; Lee et al., 2015). Incubations with $1 \mathrm{mg} / \mathrm{ml} \mathrm{NP3}$ nanoparticles for $24 \mathrm{~h}$ restored in situ CTSD enzyme activity fully in DS cells (Fig. $3 E, F ; F_{(3,391)}=63.73, p<0.0001$; one-way ANOVA). These results are consistent with deficient lysosomal acidification being a major basis for CTSD activity deficits in DS cells.

Other lysosomal hydrolases optimally active at low $\mathrm{pH}$, including lysosomal acid phosphatase (ACP2) (Gieselmann et al., 1984; Ashtari et al., 2016) and $\beta$-hexosaminidase A (HEXA) (Wendeler and Sandhoff, 2009), were similarly significantly less active in DS fibroblasts (Fig. $3 G ; t_{(10)}=7.554, p<0.0001$ for ACP2; $t_{(10)}=4.609, p=0.001$ for HEXA; unpaired $t$ test). As would be predicted, the activity of CTSB, a lysosomal protease that is stable and optimally active in the $\mathrm{pH}$ range of $6.0-6.5$ (Linebaugh et al., 1999), exhibited higher in vitro activity at the less acidified $\mathrm{pH}$ range of DS lysosomes than at the lower $\mathrm{pH}$ of lysosomes in $2 \mathrm{~N}$ cells (Fig. $3 G$; $t_{(12)}=6.976, p<0.0001$; unpaired $t$ test), and higher in situ activity in lysosomes of intact DS cells using Magic Red CatB substrate (Fig. $3 H, I ; t_{(273)}=6.093, p<$
0.0001; unpaired $t$ test). Furthermore, higher levels of CTSD and CTSB protein in DS fibroblasts could not be explained by increased transcription of their mRNA; our RNA-Seq analyses, combined with previously published RNA-Seq data (Letourneau et al., 2014; Sullivan et al., 2016), showed transcript levels for the analyzed acid hydrolases to be comparable in $2 \mathrm{~N}$ and DS fibroblasts (GSE127880; Fig. 3J; $t_{(19)}=3.338, p=0.0035$ for APP; unpaired $t$ test).

\section{siAPP knockdown of APP expression in DS fibroblasts rescues lysosomal function}

Given the role of an extra APP gene copy in causing endosome dysfunction in DS (Cataldo et al., 2008; Jiang et al., 2010, 2016), we next investigated how APP triplication may contribute to lysosome dysfunction in DS. $2 \mathrm{~N}$ and DS fibroblasts were treated by small RNA interference specifically against human APP (siAPP) or with scrambled RNA sequences (siNC) as previously described (Jiang et al., 2010). APP downregulation, confirmed by immunoblot analysis (Fig. 4A), restored lysosomal $\mathrm{pH}$ in DS fibroblasts (Fig. $4 B ; F_{(3,35)}=56.23, p<0.0001$; one-way ANOVA) fully and in situ CTSD activity partially (Fig. $4 C ; F_{(3,831)}=190.50, p<$ 0.0001; one-way ANOVA) $72 \mathrm{~h}$ after siAPP transfection. Similarly, the lowered specific CTSD activity in DS fibroblasts (Fig. $4 D ; F_{(3,12)}=9.361, p=0.0018$; one-way ANOVA) and abnormally high level of CTSD protein (Fig. $4 A, E ; F_{(3,27)}=8.203, p=$ 0.0005 ; one-way ANOVA) were also normalized by siAPP treat- 
ment without any change in its expression, as evaluated by RNASeq (Fig. $4 F ; F_{(3,20)}=29.17, p<0.0001$ for APP; $F_{(3,20)}=1.718$, $p=0.196$ for CTSD; one-way ANOVA). The expression of other lysosomal enzymes, such as CTSB, ACP2, and HEXA, were not affected by siAPP treatment (Fig. $4 F ; F_{(3,20)}=2.104, p=0.132$ for $\mathrm{CTSB} ; F_{(3,20)}=1.132, p=0.360$ for ACP $2 F_{(3,20)}=1.170, p=$ 0.346 for HEXA; one-way ANOVA). Furthermore, two important lysosomal regulators, transcription factor EB (TFEB) and transcription factor E3 (TFE3) (Martina et al., 2014, 2016; Martina and Puertollano, 2017), also remain unchanged by downregulation of APP (Fig. $4 G ; F_{(3,20)}=2.218, p=0.117$ for TFE3; one-way ANOVA). Although TFEB expression is significantly decreased in DS (Fig. $4 G ; F_{(3,20)}=31.37, p<0.0001$; one-way ANOVA), the functionally similar factor, TFE3, is more highly expressed than TFEB in brain and fibroblasts (Martina et al., 2014, 2016; Martina and Puertollano, 2017), including 10-fold higher expression in our fibroblasts (Fig. 4G) and found to be comparable in $2 \mathrm{~N}$ and DS fibroblasts (Fig. $4 G$; $t_{(10)}=0.513, p=$ 0.619 for APP; unpaired $t$ test). Therefore, the restoration of normal levels of CTSD protein in DS fibroblasts upon downregulating APP expression implies that the accumulation of a less active form of CTSD in DS is a post-transcriptional event. CTSD and related aspartyl proteinases are known to interact with certain lipids (Heinrich et al., 1999; Liao et al., 2007; Kurzawa-Akanbi et al., 2012; Amritraj et al., 2013) and other proteins (Beel et al., 2017). For example, increased glucosylceramide (GlcCer), as seen in Lewy body disease, decreases CTSD activity and increases LAMP1 and LAMP2 protein expression, possibly reflecting enlargement of lysosomes (Kurzawa-Akanbi et al., 2012). We find that exposure of DS fibroblasts to cyclodextrin, which promotes cholesterol efflux from lysosomes (Peake and Vance, 2012), lowers both lysosomal cholesterol, and GlcCer levels and reduces CTSD accumulation (E.I., J.Y., and R.A.N., unpublished observations). Protein constituents of lysosomes, such as progranulin (Beel et al., 2017) and NPC1 (Liao et al., 2007; Macías-Vidal et al., 2016), also interact directly with CTSD, influencing its activity, stability, and conceivably turnover rate. Additionally, posttranslational modifications of CTSD, such as oxidation or nitration, which have been reported for CTSD in DS (Butterfield et al., 2014 b), could alter its activity and increase its resistance to proteolysis, thereby promoting accumulation. CTSD protein levels are elevated in CTSB/CTSL double KO mice (Felbor et al., 2002), suggesting intralysosomal CTSD proteolysis, even though the involved protease(s) are unclear. In our study, lysosomal proteolysis rate is lowered in DS fibroblasts, and multiple lysosomal proteases in addition to CTSD with highly acidic $\mathrm{pH}$ optima are partially inhibited, consistent with a key role of lysosomal $\mathrm{pH}$ change. Similar CTSD changes seen in fibroblasts carrying the ATP13A2 mutation in Parkinson disease (Bourdenx and Dehay, 2016) were reversed by normalizing lysosomal $\mathrm{pH}$ with acidic nanoparticles, although the mechanism underlying CTSD accumulation was not investigated (Bourdenx et al., 2016). The possible factors influencing CTSD homeostasis, including its turnover, are therefore multiple and warrant a future comprehensive investigation.

\section{The toxic effects of APP triplication on lysosomes in DS are due mainly to APP- $\beta$ CTF}

Using antibody JRF/A $\beta$ N/25 specific for $\beta C T F$ (Mathews et al., 2002) and anti-CTSD antibody from Scripps, we observed greater APP- $\beta$ CTF colocalization with CTSD (Pearson's correlation coefficient) in DS fibroblasts (Fig. $5 A, B ; F_{(3,59)}=25.21, p<$ 0.0001; one-way ANOVA). This colocalization increased signifi- cantly in both DS and $2 \mathrm{~N}$ cells when the fibroblasts were treated with $\gamma$-secretase inhibitor L685,458, which boosts APP- $\beta$ CTF levels by inhibiting its cleavage (Fig. $5 A, B$ ) (Jiang et al., 2010; Lauritzen et al., 2016; Hung and Livesey, 2018). Quantitative immunoblot analyses confirmed that levels of APP- $\beta$ CTF were higher in the enriched lysosome fractions from DS fibroblasts than in the corresponding fractions from $2 \mathrm{~N}$ cells (Fig. $5 C, D$; $F_{(3,12)}=67.37, p<0.0001$ in total lysate; $F_{(3,12)}=8.314, p=$ 0.0029 in lysosome; one-way ANOVA).

Increased APP- $\beta$ CTF has been linked to lysosomal degradation defect seen in the neurons derived from individuals with DS (Ts21) or familial AD with APP mutation (Hung and Livesey, 2018 ). To investigate whether high APP- $\beta$ CTF levels are the principal basis for lysosomal abnormalities in DS fibroblasts, we induced elevated lysosomal APP- $\beta$ CTF levels in $2 \mathrm{~N}$ fibroblasts with the $\gamma$-secretase inhibitor L-685,485 $(10 \mu \mathrm{M})$ for $24 \mathrm{~h}$ (Fig. 5C,D). The results showed that, even in the absence of APP gene triplication or a trisomic chromosome 21 , raising APP- $\beta$ CTF in $2 \mathrm{~N}$ cells induced a significant rise in the $\mathrm{pH}$ of lysosomes (Fig. $5 E$; $F_{(3,32)}=18.93, p<0.0001$; one-way ANOVA) equal to that in DS lysosomes and suppressed lysosomal in situ CTSD activity to the levels in DS cells (Fig. $5 F, G ; F_{(3,508)}=98.19, p<0.0001$; one-way ANOVA). By contrast, blocking APP- $\beta$ CTF production using BACE1 inhibitor IV $(10 \mu \mathrm{M})$ for $24 \mathrm{~h}$ had no effect on the lysosomal $\mathrm{pH}$ of $2 \mathrm{~N}$ fibroblasts (Fig. $5 E$ ), but as expected, the lysosomal $\mathrm{pH}$ deficit in DS fibroblasts was ameliorated (Fig. $5 E$; $F_{(3,34)}=15, p<0.0001$; one-way ANOVA). In addition, in $2 \mathrm{~N}$ fibroblasts, transient transfection of a fluorescence-tagged $\beta \mathrm{CTF}$ (mCherry-C99) significantly reduced in situ CTSD activity in $2 \mathrm{~N}$ cells and further lowered CSTD activity in DS fibroblasts (Fig. $5 H, I$; transfected cell circled; $F_{(3,364)}=77.21, p<0.0001$; oneway ANOVA). We confirmed the accumulation of APP- $\beta$ CTF in the lysosomes in mCherry-C99 transfected cells incubated with dextran-Alexa-488 to mark lysosomes (Fig. $5 \mathrm{~J}$ ). Therefore, lysosomal functional defects may be the consequence of pathological accumulation of $\beta \mathrm{CTF}$ in lysosome.

\section{Cultured primary neurons from DS model mice exhibit the endosomal and lysosomal abnormalities seen in DS fibroblasts}

Extensive characterization of adult Ts2 mice (Kaur et al., 2014; Hamlett et al., 2016; Jiang et al., 2016) has documented neuropathological abnormalities equivalent in type and onset to those in the Ts65Dn trisomy model of DS, including APP-dependent neuronal endosomal anomalies (Cataldo et al., 2003), cholinergic neurodegeneration (Jiang et al., 2016), and glutamatergic neuronal deficits (Kaur et al., 2014). The signature AD-related endosome enlargement develops by 2-3 months after birth in both mouse models (Jiang et al., 2016), but surprisingly, primary cultures of cortical neurons from Ts2 mice, despite their immaturity, develop the typical AD-related enlargement of early (Fig. $6 A, B ; t_{(116)}=4.550, p<0.0001$ for size $0.01-0.5 \mu \mathrm{m}^{2} ; t_{(116)}=$ 5.617, $p<0.0001$ for size $0.51-1.4 \mu \mathrm{m}^{2} ; t_{(110)}=5.175, p<$ 0.0001 for size $1.41-3.0 \mu \mathrm{m}^{2}$; unpaired $t$ test) and late endosomes (Fig. $6 C$; $t_{(117)}=2.649, p=0.0092$ for size $1.41-3.0 \mu \mathrm{m}^{2}$; unpaired $t$ test), suggesting that stress conditions in cultures can be permissive for earlier onset of endosomal pathology. We further established that lysosomal $\mathrm{pH}$ is abnormally elevated (Fig. 6D; $t_{(14)}=4.918, p=0.0002$; unpaired $t$ test) and that CTSD activation in lysosomes in situ (Fig. $6 E, G ; t_{(95)}=2.373, p=0.019$ for CTSD; $t_{(70)}=0.252, p=0.802$ for CTSB; unpaired $t$ test) and total activity in vitro are significantly lowered compared with levels in $2 \mathrm{~N}$ neurons (Fig. $6 H ; t_{(4)}=4.216, p=0.0135$; unpaired 
A



E

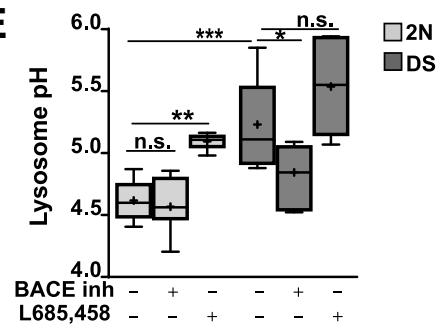

H
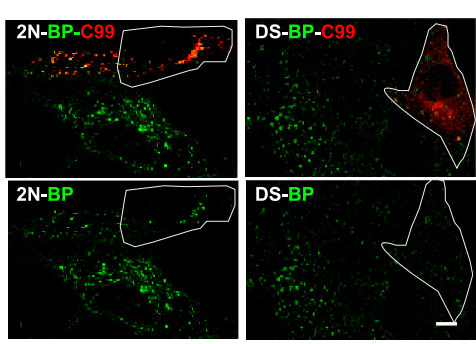

B

Pearson's R (CTSD \& $\beta C T F)$


C

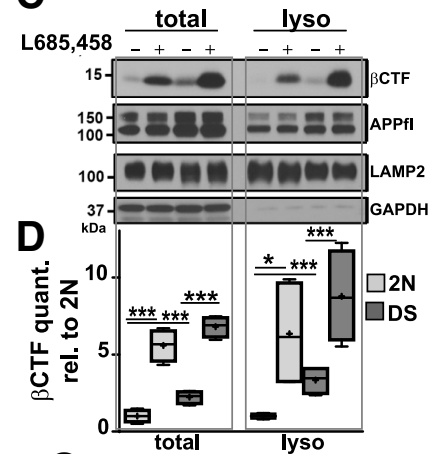

G

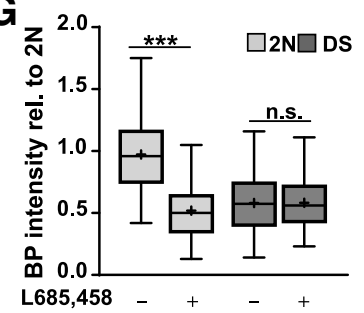

J

L685,458
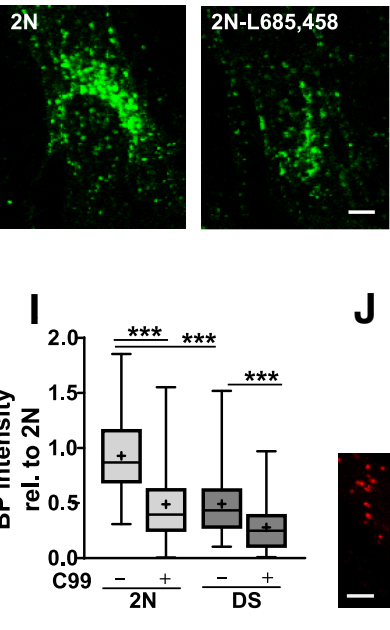

C99/Lyso(dextran488)
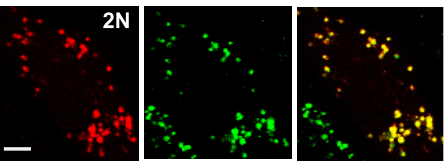

Figure 5. Accumulation of $\beta$ CTF in lysosome of DS fibroblast and $\beta C T F$ dependence of lysosomal CTSD activity in $2 \mathrm{~N}$ and DS fibroblasts. $A$, Representative images of colabeling of CTSD (red) and APP- $\beta$ CTF (green) antibodies in $2 \mathrm{~N}$ and DS fibroblasts treated with either vehicle (DMSO) or $\gamma$-secretase inhibitor, L-685,458 (10 $\mu \mathrm{m}$ for $24 \mathrm{~h}$ ), and (B) the Pearson correlation coefficient between the CTSD and $\beta$ CTF ( $n \geq 15$ cells). C, Representative Western blot of APP- $\beta$ CTF in total lysate and lysosome after lysosomal isolation with dextran-conjugated magnetite beads ( $n=3$ replicates), and (D) its quantitation in total cellular (load $15 \mu \mathrm{g}$ protein/lane) and lysosomal fractions (load $5 \mu \mathrm{g}$ protein/lane). $\boldsymbol{E}$, Lysosome pH measured by LysoSensor Yellow/Blue dextran in $2 \mathrm{~N}$ and DS

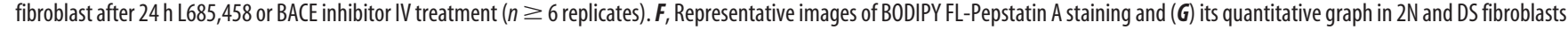
treated with DMSO or L685,458 ( $n \geq 150$ cells). $\boldsymbol{H}$, Representative images of BODIPY FL-Pepstatin A staining, with arrow indicating cell with positive $m$ Cherry-C99 transfection, and (I) BP quantitative graph in $2 \mathrm{~N}$ fibroblasts either transfected with or without $\mathrm{mCherry-C99}$ ( $n \geq 62$ cells). J, Representative confocal colocalization image of $\mathrm{mCherry-C99}$ and dextran-AlexaFluor-488 uptake as lysosomal marker. + sign indicates mean in Bar and Whiskers plots. n.s., not significant, ${ }^{*} p \leq 0.05,{ }^{* *} p \leq 0.01,{ }^{* * *} p \leq 0.005$. Scale bar, $5 \mu \mathrm{m}$.

$t$ test), although CTSD protein did not accumulate (Fig. 6I,J; $t_{(7)}=0.375, p=0.719$; unpaired $t$ test) and CTSB activities were not altered by this stage of neuronal development (Fig. $6 \mathrm{~F}-\mathrm{H}$; $t_{(8)}=0.467, p=0.653$; unpaired $t$ test).

Consistent with presence of the extra copy of APP, primary Ts2 neurons at DIV 7 showed commensurately higher APP (1.7fold; $t_{(6)}=3.402, p=0.0145$; unpaired $t$ test) and even higher $\operatorname{APP}-\beta C T F\left(3.3\right.$-fold; $t_{(6)}=2.814, p=0.0306$; unpaired $t$ test) protein levels (Fig. $6 I, J$ ). As previously observed in DS fibroblasts, lowering APP expression using siRNA diminished APP protein levels significantly in both $\mathrm{Ts} 2$ and $2 \mathrm{~N}$ neuronal cultures (Fig. $7 A-C ; F_{(3,45)}=67.19, p<0.0001$; one-way ANOVA). In Ts2 neurons, APP downregulation normalized the sizes of enlarged EEA1-positive early endosomes without affecting $2 \mathrm{~N}$ endosomes (Fig. $7 D, E ; F_{(3,174)}=8.849, p<0.0001$ for size $0.01-0.5 \mu \mathrm{m}^{2}$; $F_{(3,174)}=15.98, p<0.0001$ for size $0.51-1.4 \mu \mathrm{m}^{2} ; F_{(3,174)}=$ 12.66, $p<0.0001$ for size 1.41-3.0 $\mu^{2}$; one-way ANOVA). Lowering APP levels also restored normal levels of in situ lysosomal CTSD activation (Fig. $7 F, G ; F_{(3,140)}=19.24, p<0.0001$; one-way ANOVA), implying APP-dependent lysosomal impairment. Finally, CTSD specific activity was lowered in brain homogenates from 8-month-old Ts2 mice (Fig. $7 H ; F_{(2,10)}=10.70$, $p=0.0074$; one-way ANOVA). BACE1 gene dosage reduction upon crossing TS2 mice with $\mathrm{BACE}^{+/-}$mice restored CTSD activity to the normal level seen in the $2 \mathrm{~N}$ brain homogenates (Fig. $7 H ; F_{(2,10)}=10.70, p=0.0074$; one-way ANOVA).

\section{Discussion}

Emerging genetic, neuropathological, and biological evidence implicates dysfunction of the endosomal-lysosomal pathway in AD pathogenesis at early and late stages of disease (Nixon, 2017) as well as in other late-onset neurodegenerative diseases (Nixon, 2013; Stoka et al., 2016; Vidoni et al., 2016; Colacurcio et al., 2018). In this investigation, we uncovered AD-related lysosomal functional deficits in primary fibroblasts from individuals with DS, representing the authentic trisomy 21 disorder, and in neurons from Ts 2 mice modeling DS. Our findings show that modest elevation of endogenous APP in DS is sufficient to induce lysosomal disruption and that a rise in levels of APP- $\beta$ CTF in lysosomes is the most proximal molecular cause of the disruption. Given that APP- $\beta$ CTF levels are also higher in AD brain, even though APP levels are not detectably elevated (Pera et al., 2013; Kim et al., 2016), our results suggest that these early APP- $\beta$ CTFmediated lysosomal deficits may catalyze progressive lysosomal 

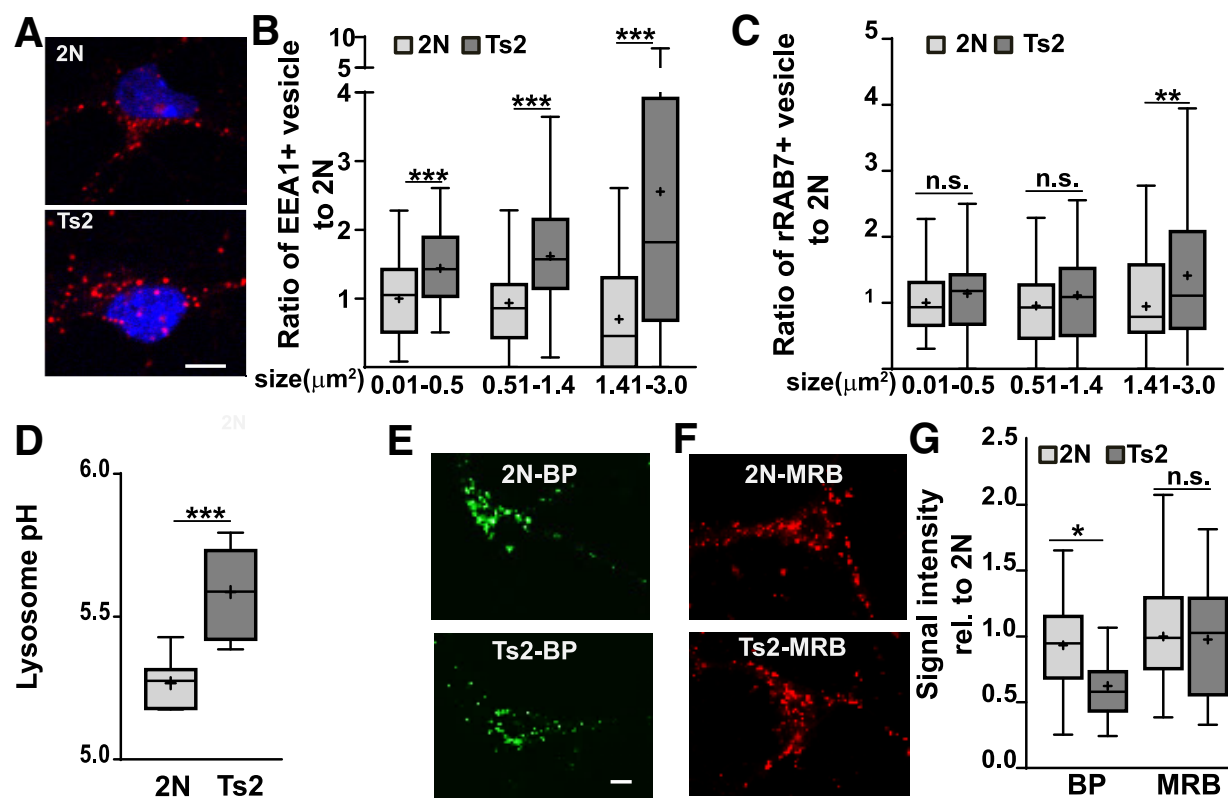

E
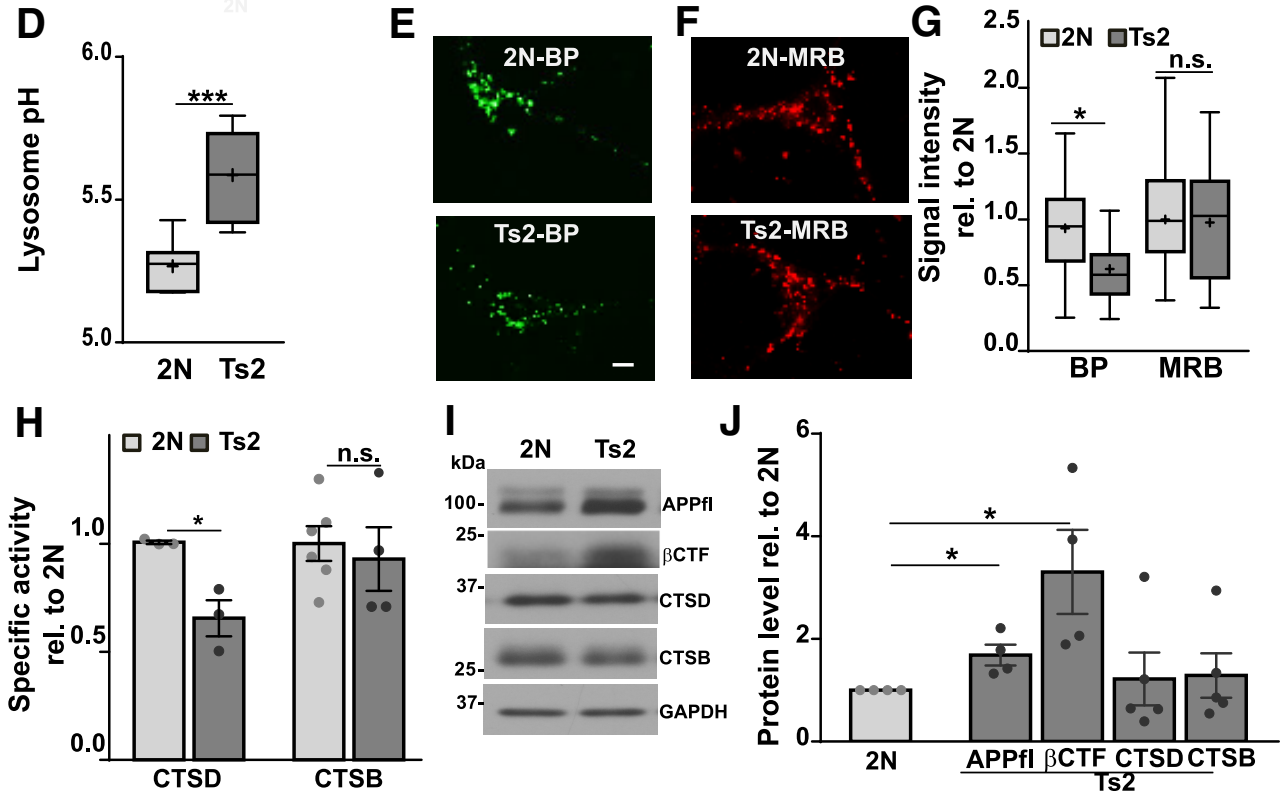

Figure 6. Endosomal and lysosomal defects in Ts2 mouse cortical neuronal culture. $\boldsymbol{A}$, Representative confocal images of EEA1 staining of $2 \mathrm{~N}$ and $\mathrm{Ts} 2 \mathrm{neurons}$, and ( $\boldsymbol{B}$ ) quantification of EEA1-positive ( $n \geq 58$ neurons) and (C) Rab7-positive endosomes ( $n \geq 59$ neurons). D, Lysosome pH of $2 \mathrm{~N}$ and Ts2 neurons measured by LysoSensor Yellow/Blue dextran ( $n=8$ replicates). Representative images of (E) BODIPY FL-Pepstatin A and (F) Magic Red CatB (MRB) labeling and (G) their intensity quantification in $2 \mathrm{~N}$ and Ts2 neurons ( $n \geq 33$ neurons). $\boldsymbol{H}$, Scatter plot with mean designated by bars showing specific activity of CTSD and CTSB measured by in vitro enzymatic activity assay $(n=3$ replicates). $\boldsymbol{I}$, Representative Western blot and $(J)$ scatter plot with mean designated by bars showing quantitation of APP, $\beta$ CTF, CTSD, and CTSB in $2 N$ and Ts2 neurons, GAPDH as internal control ( $n \geq 4$ replicates). + sign indicates mean in Bar and Whiskers plots. n.S., not significant, ${ }^{*} p \leq 0.05,{ }^{* *} p \leq 0.01,{ }^{* * *} p \leq 0.005$. Scale bar, $5 \mu \mathrm{m}$.

corruption via the buildup of intraneuronal $\mathrm{A} \beta$ and other oxidized substrates that further impede substrate hydrolysis, damage lysosomal membranes, and catalyze neurodegeneration in AD (Nixon, 2017; Colacurcio et al., 2018). In this regard, lysosomal alterations develop months before $\beta$-amyloid deposition in $\mathrm{AD}$ mouse models with late-onset amyloidosis (J.H.L. and R.A.N., manuscript in preparation). APP- $\beta$ CTF has also been previously linked to lysosomal dysfunction in $\mathrm{AD}$ models involving overexpressed forms of FAD-mutated APP with or without additional overexpression of other mutated human $\mathrm{AD}$ genes (Lauritzen et al., 2012, 2016; Yang et al., 2014; Kaur et al., 2017; Bourgeois et al., 2018), and in iPSC generated Ts21 neurons (Hung and Livesey, 2018).

We discovered that luminal acidification of lysosomes is significantly impaired in DS and primarily responsible for disrupting lysosomal hydrolase activities and CTSD protein buildup. We established deficient acidification by direct ratiometric measurement in lysosomes in situ and confirmed that ALs were incompletely acidified using an mRFP-eGFP-LC3 construct transfected into DS cells in conjunction with dextranAlexaFluor-647 uptake. Notably, impaired autolysosomal acidification is the earliest autophagy alteration seen in $\mathrm{AD}$ mouse models expressing a neuronal mRFP-eGFP-LC3 transgene and accompanies the appearance of intraneuronal APP- $\beta$ CTF (Lee et al., 2019) (J.H.L. and R.A.N., manuscript in preparation). Abnormally elevated lysosomal $\mathrm{pH}$ in both DS fibroblasts and primary cortical neurons from Ts2 mice was sufficient to depress CTSD activation, a process optimally requiring an intralysosomal $\mathrm{pH}$ of 4.0-4.5 (Barrett, 1970; Cunningham and Tang, 1976). The restoration of CTSD activation in DS lysosomes by targeted acidic nanoparticles indicated that defective acidification in DS is the primary basis for the impaired activities of multiple acid hydrolases with exceptionally low $\mathrm{pH}$ optima.

Lysosomal acidification is maintained principally by the vacuolar-type $\mathrm{H}^{+}$-ATPase complex (vATPase), which imports hydrogen ions into the lysosome (Mindell, 2012). Mutations or imbalance of the subunits or accessory proteins composing the proton pump impair acidification and lead to neurodegeneration in numerous congenital diseases (Colacurcio and Nixon, 2016). Moreover, in familial AD caused by presenilin 1 (PSEN1) mutations, failed lysosomal delivery of the V0a1 subunit markedly impairs lysosomal acidification, inducing acid hydrolase inhibition and lysosomal substrate buildup in patient primary fibroblasts (Lee et al., 2010; Martín-Maestro et al., 2017) and iPSC neurons derived from these fibroblasts (Martín-Maestro et al., 2017; Hung and Livesey, 2018) and in brains of PSEN1/APP mice 
A

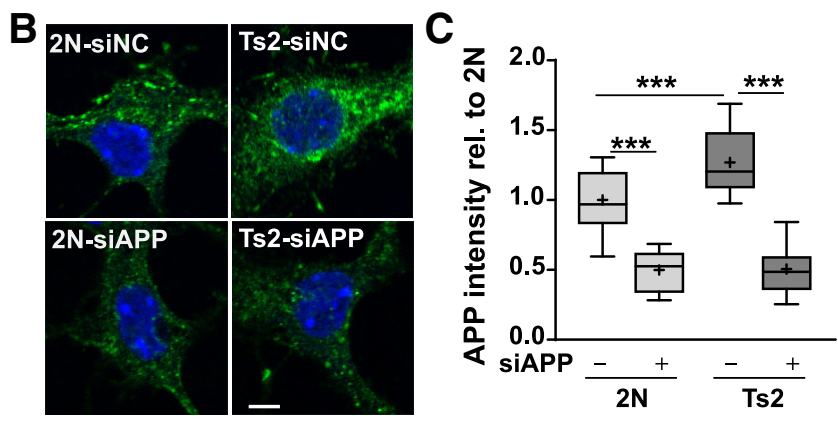

E

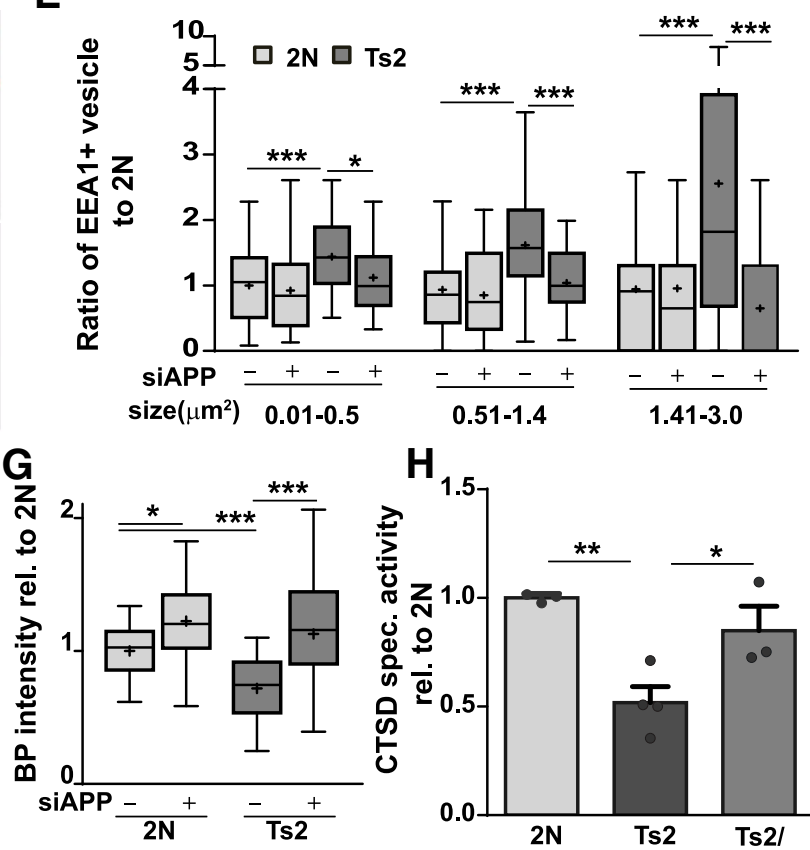

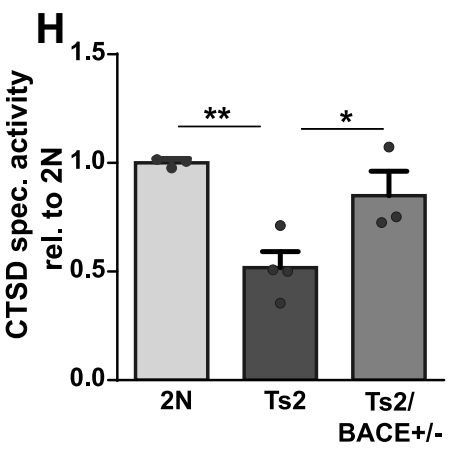

Figure 7. Restoration of endosomal and lysosomal defects in Ts2 mice. $\boldsymbol{A}$, Representative Western blot ( $n=4$ replicates) and (B) representative confocal image of APP labeling and ( $\boldsymbol{C}$ ) quantitation of APP in $2 \mathrm{~N}$ and Ts2 neurons after treatment with siRNA for either negative controls (siNC) or for mouse-specific APP (siAPP) for $72 \mathrm{~h}$ ( $n=16$ neurons). $\boldsymbol{D}$, Representative confocal images of EEA1 staining and $(\boldsymbol{E})$ quantitation of EEA1-positive endosomes of $2 \mathrm{~N}$ and Ts2 neurons $72 \mathrm{~h}$ after siRNA transfection ( $n \geq 30$ neurons). $\boldsymbol{F}$, Representative images of BODIPY FL-Pepstatin A and $(\boldsymbol{G})$ quantitation of $2 \mathrm{~N}$ and Ts2 neurons $72 \mathrm{~h}$ after siRNA transfection $\left(n=36\right.$ neurons). $\boldsymbol{H}$, Specific in vitro activity of (TSD in $2 \mathrm{~N}$, Ts2, and Ts2BACE ${ }^{+/-}$mouse brain homogenate ( $n \geq 3$ mice). + sign indicates mean in Bar and Whiskers plots. ${ }^{*} p \leq 0.05,{ }^{* *} p \leq 0.01,{ }^{* * *} p \leq 0.005$. Scale bar, $5 \mu \mathrm{m}$.

(Avrahami et al., 2013). Lysosomal pH and CTSD activity are similarly, impaired in primary glia cultured from brains of a mutant APP model of AD (CRND8) (Xue et al., 2014). We have also conducted an extensive analysis of the molecular mechanism underlying the lysosomal acidification deficit in DS fibroblasts (E.I., Y.J., R.A.N., unpublished observations). We have identified a direct physical interaction of lysosomal-associated APP- $\beta$ CTF with the cytosol-exposed domain of the transmembrane $\mathrm{VOa}$ subunit of the vATPase. Competition by APP- $\beta C T F$ with specific $\mathrm{V} 1$ subunits for binding to the V0al subunit impedes association of the V1 and V0 sectors of the complex. The level of V1 sector association with the $\mathrm{V} 0$ sector regulates ATPase and proton pump activities of the vATPase complex on lysosomes (Cotter et al., 2015). Impaired vATPase assembly, like the deficits reported in the present study, is rescued by specifically lowering APP$\beta C T F$ levels (E.I., Y.J., R.A.N., unpublished observations). The identification of a lysosomal acidification defect in DS and DS model neurons therefore implicates APP via its BACE1-cleaved metabolite as a second key etiologic factor in $\mathrm{AD}$, together with PSEN1, in directly dysregulating vATPase. The findings support an emerging concept that acidification impairment may be a proximal biochemical event in $\mathrm{AD}$, common to multiple genetic risk factors that cause or promote AD (Lee et al., 2010; Xue et al., 2014; Vidoni et al., 2016).

CTSD activation is deficient in various neuropathologic states and as a result of genetic mutations (Colacurcio and Nixon, 2016; Vidoni et al., 2016). CTSD is a ubiquitous protease, but its unique importance in brain is illustrated by the relatively selective neurodevelopmental and progressive neurodegenerative phenotype induced by the loss-of-function CTSD mutations causing the congenital disorder neuronal ceroid lipofuscinosis CLN10 (Tyynelä et al., 2000; Siintola et al., 2006). Notably, even a partial loss of CTSD function is associated with CNS deficits in humans (Mamo et al., 2012; Tatti et al., 2013). CTSD is considered as a key protease in the lysosomal degradation of many pathogenic proteins in addition to APP metabolites, including $\alpha$-synuclein and huntingtin (Kegel et al., 2000; Sevlever et al., 2008). CTSD gene transcription in neurons is upregulated at early stages of $\mathrm{AD}$ (Cataldo et al., 1995) and is accompanied by the accumulation of CTSD forms with decreased activity (P.S.M. and R.A.N., manuscript in preparation). Furthermore, we previously reported that ventricular CSF obtained postmortem from AD 
patients has substantially elevated levels of CTSD with markedly lowered specific activity compared with CSF from individuals with Huntington's disease or from non-neurologic disease controls (Schwagerl et al., 1995).

We observed that, in addition to CTSD, acid hydrolases acting on lipids, lipoproteins, and glycoproteins are also partially inactivated, suggesting even broader metabolic dysfunction in DS lysosomes than just proteolysis. Notably, CTSB, a lysosomal exopeptidase with a $\mathrm{pH}$ optimum in the mildly acidic range (Barrett and Kirschke, 1981), was more active in DS lysosomes. Although this situation possibly confers a degree of compensatory proteolysis, an imbalance of endopeptidase and exopeptidase activities could potentially generate peptide fragments that resist proteolysis, aggregate, and/or have toxicity (Khurana et al., 2010). In any event, lysosomal turnover of both autophagic and endocytic substrates was deficient in DS cells. That substrate accumulation worsened after strong induction of mTOR-dependent autophagy is notable in light of the abnormally high level of mTOR activation seen in the brains of DS mouse models (Iyer et al., 2014; Perluigi et al., 2014) and in DS fibroblasts (Bordi et al., manuscript submitted) also exhibiting markedly lowered baseline AP formation and mitophagy, which can be restored by selectively inhibiting TORC1 and TORC2 (M. Bordi, manuscript submitted). Lowered baseline autophagy/mitophagy induction in DS may possibly protect against inefficient DS lysosomes by reducing substrate delivery. Nevertheless, the protein damage and oxidative stress from damaged mitochondria (Piccoli et al., 2013), which increases as cells age, are expected to upregulate autophagy and promote lysosomal failure similar to conditions seen in neurons in AD brain (Bordi et al., 2016).

In conclusion, our findings indicate that APP- $\beta \mathrm{CTF}$ elevation is necessary and sufficient to impair lysosomal function in the context of DS and, when APP- $\beta$ CTF levels are artificially raised, even in control $2 \mathrm{~N}$ cells. This conclusion, however, does not exclude the possible additional influences of other triplicated chromosome 21 genes or metabolic factors, such as oxidative stress, lipid peroxidation, and protein nitration (Perluigi and Butterfield, 2012; Butterfield et al., 2014a), which are likely additive factors in corrupting lysosome functions. Lysosomal deficits in DS add to the known endosomal anomalies known to develop in DS within the same vesicular trafficking pathway, which include some signature features of early AD and are also APP-dependent and mediated by APP- $\beta$ CTF (Jiang et al., 2010, 2016; Hung and Livesey, 2018). That these effects in DS are demonstrable in the authentic trisomy 21 disorder, rather than in only genetically manipulated model systems, underscores their relevance to pathogenic mechanisms and their importance as therapeutic targets in $\mathrm{DS}$ and $\mathrm{AD}$.

\section{References}

Amritraj A, Wang Y, Revett TJ, Vergote D, Westaway D, Kar S (2013) Role of cathepsin D in U18666A-induced neuronal cell death: potential implication in Niemann-Pick type C disease pathogenesis. J Biol Chem 288: $3136-3152$.

Ashtari N, Jiao X, Rahimi-Balaei M, Amiri S, Mehr SE, Yeganeh B, Marzban H (2016) Lysosomal acid phosphatase biosynthesis and dysfunction: a mini review focused on lysosomal enzyme dysfunction in brain. Curr Mol Med 16:439-446.

Auteri JS, Okada A, Bochaki V, Dice JF (1983) Regulation of intracellular protein degradation in IMR-90 human diploid fibroblasts. J Cell Physiol 115:167-174.

Avrahami L, Farfara D, Shaham-Kol M, Vassar R, Frenkel D, EldarFinkelman H (2013) Inhibition of glycogen synthase kinase-3 ameliorates beta-amyloid pathology and restores lysosomal acidification and mammalian target of rapamycin activity in the Alzheimer disease mouse model: in vivo and in vitro studies. J Biol Chem 288:1295-1306.

Baltazar GC, Guha S, Lu W, Lim J, Boesze-Battaglia K, Laties AM, Tyagi P, Kompella UB, Mitchell CH (2012) Acidic nanoparticles are trafficked to lysosomes and restore an acidic lysosomal $\mathrm{pH}$ and degradative function to compromised ARPE-19 cells. PLoS One 7:e49635.

Barrett AJ (1970) Cathepsin D: purification of isoenzymes from human and chicken liver. Biochem J 117:601-607.

Barrett AJ, Kirschke H (1981) Cathepsin B, cathepsin H, and cathepsin L. Methods Enzymol 80:535-561.

Beel S, Moisse M, Damme M, De Muynck L, Robberecht W, Van Den Bosch L, Saftig P, Van Damme P (2017) Progranulin functions as a cathepsin D chaperone to stimulate axonal outgrowth in vivo. Hum Mol Genet 26:2850-2863.

Boland B, Kumar A, Lee S, Platt FM, Wegiel J, Yu WH, Nixon RA (2008) Autophagy induction and autophagosome clearance in neurons: relationship to autophagic pathology in Alzheimer's disease. J Neurosci 28:6926-6937.

Bordi M, Berg MJ, Mohan PS, Peterhoff CM, Alldred MJ, Che S, Ginsberg SD, Nixon RA (2016) Autophagy flux in CAl neurons of Alzheimer hippocampus: increased induction overburdens failing lysosomes to propel neuritic dystrophy. Autophagy 12:2467-2483.

Bourdenx M, Dehay B (2016) What lysosomes actually tell us about Parkinson's disease? Ageing Res Rev 32:140-149.

Bourdenx M, Daniel J, Genin E, Soria FN, Blanchard-Desce M, Bezard E, Dehay B (2016) Nanoparticles restore lysosomal acidification defects: implications for Parkinson and other lysosomal-related diseases. Autophagy 12:472-483.

Bourgeois A, Lauritzen I, Lorivel T, Bauer C, Checler F, Pardossi-Piquard R (2018) Intraneuronal accumulation of C99 contributes to synaptic alterations, apathy-like behavior, and spatial learning deficits in 3xTgAD and 2xTgAD mice. Neurobiol Aging 71:21-31.

Bright NA, Gratian MJ, Luzio JP (2005) Endocytic delivery to lysosomes mediated by concurrent fusion and kissing events in living cells. Curr Biol 15:360-365.

Butterfield DA, Gu L, Di Domenico F, Robinson RA (2014a) Mass spectrometry and redox proteomics: applications in disease. Mass Spectrom Rev 33:277-301.

Butterfield DA, Di Domenico F, Swomley AM, Head E, Perluigi M (2014b) Redox proteomics analysis to decipher the neurobiology of Alzheimerlike neurodegeneration: overlaps in Down's syndrome and Alzheimer's disease brain. Biochem J 463:177-189.

Cataldo AM, Barnett JL, Berman SA, Li J, Quarless S, Bursztajn S, Lippa C, Nixon RA (1995) Gene expression and cellular content of cathepsin D in Alzheimer's disease brain: evidence for early up-regulation of the endosomal-lysosomal system. Neuron 14:671-680.

Cataldo AM, Barnett JL, Pieroni C, Nixon RA (1997) Increased neuronal endocytosis and protease delivery to early endosomes in sporadic Alzheimer's disease: neuropathologic evidence for a mechanism of increased beta-amyloidogenesis. J Neurosci 17:6142-6151.

Cataldo AM, Peterhoff CM, Troncoso JC, Gomez-Isla T, Hyman BT, Nixon RA (2000) Endocytic pathway abnormalities precede amyloid beta deposition in sporadic Alzheimer's disease and Down syndrome: differential effects of APOE genotype and presenilin mutations. J Pathol 157:277286.

Cataldo AM, Petanceska S, Peterhoff CM, Terio NB, Epstein CJ, Villar A, Carlson EJ, Staufenbiel M, Nixon RA (2003) APP gene dosage modulates endosomal abnormalities of Alzheimer's disease in a segmental trisomy 16 mouse model of Down syndrome. J Neurosci 23:6788 6792.

Cataldo AM, Mathews PM, Boiteau AB, Hassinger LC, Peterhoff CM, Jiang Y, Mullaney K, Neve RL, Gruenberg J, Nixon RA (2008) Down syndrome fibroblast model of Alzheimer-related endosome pathology: accelerated endocytosis promotes late endocytic defects. J Pathol 173:370-384

Chen J, Burghart A, Derecskei-Kovacs A, Burgess K (2000) 4,4-Difluoro4-bora-3a,4a-diaza-s-indacene (BODIPY) dyes modified for extended conjugation and restricted bond rotations. J Org Chem 65:2900-2906.

Chresta CM, Davies BR, Hickson I, Harding T, Cosulich S, Critchlow SE, Vincent JP, Ellston R, Jones D, Sini P, James D, Howard Z, Dudley P, Hughes G, Smith L, Maguire S, Hummersone M, Malagu K, Menear K, Jenkins R, et al. (2010) AZD8055 is a potent, selective, and orally 
bioavailable ATP-competitive mammalian target of rapamycin kinase inhibitor with in vitro and in vivo antitumor activity. Cancer Res 70:288-298.

Colacurcio DJ, Nixon RA (2016) Disorders of lysosomal acidification: the emerging role of $\mathrm{v}$-ATPase in aging and neurodegenerative disease. Ageing Res Rev 32:75-88.

Colacurcio DJ, Pensalfini A, Jiang Y, Nixon RA (2018) Dysfunction of autophagy and endosomal-lysosomal pathways: roles in pathogenesis of Down syndrome and Alzheimer's disease. Free Radic Biol Med 114:40-51.

Cotter K, Stransky L, McGuire C, Forgac M (2015) Recent insights into the structure, regulation, and function of the V-ATPases. Trends Biochem Sci 40:611-622.

Cuervo AM, Stefanis L, Fredenburg R, Lansbury PT, Sulzer D (2004) Impaired degradation of mutant $\alpha$-synuclein by chaperone-mediated autophagy. Science 305:1292-1295.

Cunningham M, Tang J (1976) Purification and properties of cathepsin D from porcine spleen. J Biol Chem 251:4528-4536.

Dehay B, Martinez-Vicente M, Caldwell GA, Caldwell KA, Yue Z, Cookson MR, Klein C, Vila M, Bezard E (2013) Lysosomal impairment in Parkinson's disease. Mov Disord 28:725-732.

Diwu Z, Chen CS, Zhang C, Klaubert DH, Haugland RP (1999) A novel acidotropic $\mathrm{pH}$ indicator and its potential application in labeling acidic organelles of live cells. Chem Biol 6:411-418.

Doran E, Keator D, Head E, Phelan MJ, Kim R, Totoiu M, Barrio JR, Small GW, Potkin SG, Lott IT (2017) Down syndrome, partial trisomy 21, and absence of Alzheimer's disease: the role of APP. J Alzheimers Dis 56:459470.

Duchon A, Raveau M, Chevalier C, Nalesso V, Sharp AJ, Herault Y (2011) Identification of the translocation breakpoints in the Ts65Dn and Ts1Cje mouse lines: relevance for modeling Down syndrome. Mamm Genome 22:674-684.

Felbor U, Kessler B, Mothes W, Goebel HH, Ploegh HL, Bronson RT, Olsen BR (2002) Neuronal loss and brain atrophy in mice lacking cathepsins B and L. Proc Natl Acad Sci U S A 99:7883-7888.

Gamba P, Testa G, Gargiulo S, Staurenghi E, Poli G, Leonarduzzi G (2015) Oxidized cholesterol as the driving force behind the development of Alzheimer's disease. Front Aging Neurosci 7:119.

Gauthier SA, Pérez-González R, Sharma A, Huang FK, Alldred MJ, Pawlik M, Kaur G, Ginsberg SD, Neubert TA, Levy E (2017) Enhanced exosome secretion in Down syndrome brain: a protective mechanism to alleviate neuronal endosomal abnormalities. Acta Neuropathol Commun 5:65.

Gee KR, Sun WC, Bhalgat MK, Upson RH, Klaubert DH, Latham KA, Haugland RP (1999) Fluorogenic substrates based on fluorinated umbelliferones for continuous assays of phosphatases and beta-galactosidases. Anal Biochem 273:41-48.

Gieselmann V, Hasilik A, von Figura K (1984) Tartrate-inhibitable acid phosphatase: purification from placenta, characterization and subcellular distribution in fibroblasts. Hoppe Seylers Z Physiol Chem 365:651-660.

Giudetti AM, Romano A, Lavecchia AM, Gaetani S (2016) The role of brain cholesterol and its oxidized products in Alzheimer's disease. Curr Alzheimer Res 13:198-205.

Goutagny R, Gu N, Cavanagh C, Jackson J, Chabot JG, Quirion R, Krantic S, Williams S (2013) Alterations in hippocampal network oscillations and theta-gamma coupling arise before abeta overproduction in a mouse model of Alzheimer's disease. Eur J Neurosci 37:1896-1902.

Haass C, Selkoe DJ (1993) Cellular processing of beta-amyloid precursor protein and the genesis of amyloid beta-peptide. Cell 75:1039-1042.

Hamlett ED, Boger HA, Ledreux A, Kelley CM, Mufson EJ, Falangola MF, Guilfoyle DN, Nixon RA, Patterson D, Duval N, Granholm AC (2016) Cognitive impairment, neuroimaging, and Alzheimer neuropathology in mouse models of Down syndrome. Curr Alzheimer Res 13:35-52.

Heinrich M, Wickel M, Schneider-Brachert W, Sandberg C, Gahr J, Schwandner R, Weber T, Saftig P, Peters C, Brunner J, Krönke M, Schütze S (1999) Cathepsin $\mathrm{D}$ targeted by acid sphingomyelinase-derived ceramide. EMBO J 18:5252-5263.

Holsinger RM, McLean CA, Beyreuther K, Masters CL, Evin G (2002) Increased expression of the amyloid precursor beta-secretase in Alzheimer's disease. Ann Neurol 51:783-786.

Hung CO, Livesey FJ (2018) Altered $\gamma$-secretase processing of APP disrupts lysosome and autophagosome function in monogenic Alzheimer's disease. Cell Rep 25:3647-3660.e2.

Ivy GO, Kanai S, Ohta M, Smith G, Sato Y, Kobayashi M, Kitani K (1989) Lipofuscin-like substances accumulate rapidly in brain, retina and internal organs with cysteine protease inhibition. Adv Exp Med Biol 266:3145; discussion 45-47.

Iyer AM, van Scheppingen J, Milenkovic I, Anink JJ, Adle-Biassette H, Kovacs GG, Aronica E (2014) mTOR hyperactivation in Down syndrome hippocampus appears early during development. J Neuropathol Exp Neurol 73:671-683.

Jiang Y, Mullaney KA, Peterhoff CM, Che S, Schmidt SD, Boyer-Boiteau A, Ginsberg SD, Cataldo AM, Mathews PM, Nixon RA (2010) Alzheimer's-related endosome dysfunction in Down syndrome is abetaindependent but requires APP and is reversed by BACE- 1 inhibition. Proc Natl Acad Sci U S A 107:1630-1635.

Jiang Y, Rigoglioso A, Peterhoff CM, Pawlik M, Sato Y, Bleiwas C, Stavrides P, Smiley JF, Ginsberg SD, Mathews PM, Levy E, Nixon RA (2016) Partial BACE1 knockdown in a Down syndrome mouse model blocks Alzheimer-related endosomal anomalies and cholinergic neurodegeneration: role of APP-CTF. Neurobiol Aging 39:8.

Kaur G, Sharma A, Xu W, Gerum S, Alldred MJ, Subbanna S, Basavarajappa BS, Pawlik M, Ohno M, Ginsberg SD, Wilson DA, Guilfoyle DN, Levy E (2014) Glutamatergic transmission aberration: a major cause of behavioral deficits in a murine model of Down's syndrome. J Neurosci 34: 5099-5106.

Kaur G, Pawlik M, Gandy SE, Ehrlich ME, Smiley JF, Levy E (2017) Lysosomal dysfunction in the brain of a mouse model with intraneuronal accumulation of carboxyl terminal fragments of the amyloid precursor protein. Mol Psychiatry 22:981-989.

Kegel KB, Kim M, Sapp E, McIntyre C, Castaño JG, Aronin N, DiFiglia M (2000) Huntingtin expression stimulates endosomal-lysosomal activity, endosome tubulation, and autophagy. J Neurosci 20:7268-7278.

Khurana V, Elson-Schwab I, Fulga TA, Sharp KA, Loewen CA, Mulkearns E, Tyynelä J, Scherzer CR, Feany MB (2010) Lysosomal dysfunction promotes cleavage and neurotoxicity of tau in vivo. PLoS Genet 6:e1001026.

Kim S, Sato Y, Mohan PS, Peterhoff C, Pensalfini A, Rigoglioso A, Jiang Y, Nixon RA (2016) Evidence that the rab5 effector APPL1 mediates APPbetaCTF-induced dysfunction of endosomes in Down syndrome and Alzheimer's disease. Mol Psychiatry 21:707-716.

Kimura S, Noda T, Yoshimori T (2007) Dissection of the autophagosome maturation process by a novel reporter protein, tandem fluorescenttagged LC3. Autophagy 3:452-460.

Komatsu M, Waguri S, Ueno T, Iwata J, Murata S, Tanida I, Ezaki J, Mizushima N, Ohsumi Y, Uchiyama Y, Kominami E, Tanaka K, Chiba T (2005) Impairment of starvation-induced and constitutive autophagy in Atg7-deficient mice. J Cell Biol 169:425-434.

Korbel JO, Tirosh-Wagner T, Urban AE, Chen XN, Kasowski M, Dai L, Grubert F, Erdman C, Gao MC, Lange K, Sobel EM, Barlow GM, Aylsworth AS, Carpenter NJ, Clark RD, Cohen MY, Doran E, Falik-Zaccai T, Lewin SO, Lott IT, et al. (2009) The genetic architecture of Down syndrome phenotypes revealed by high-resolution analysis of human segmental trisomies. Proc Natl Acad Sci U S A 106:12031-12036.

Kurzawa-Akanbi M, Hanson PS, Blain PG, Lett DJ, McKeith IG, Chinnery PF, Morris CM (2012) Glucocerebrosidase mutations alter the endoplasmic reticulum and lysosomes in Lewy body disease. J Neurochem 123:298 309.

Lauritzen I, Pardossi-Piquard R, Bauer C, Brigham E, Abraham JD, Ranaldi S, Fraser P, St-George-Hyslop P, Le Thuc O, Espin V, Chami L, Dunys J, Checler F (2012) The beta-secretase-derived C-terminal fragment of betaAPP, C99, but not Abeta, is a key contributor to early intraneuronal lesions in triple-transgenic mouse hippocampus. J Neurosci 32:16243$16255 \mathrm{a}$.

Lauritzen I, Pardossi-Piquard R, Bourgeois A, Pagnotta S, Biferi MG, Barkats M, Lacor P, Klein W, Bauer C, Checler F (2016) Intraneuronal aggregation of the beta-CTF fragment of APP (C99) induces abetaindependent lysosomal-autophagic pathology. Acta Neuropathol 132: 257-276.

Lee JH, Yu WH, Kumar A, Lee S, Mohan PS, Peterhoff CM, Wolfe DM, Martinez-Vicente M, Massey AG, Sovak G, Uchiyama Y, Westaway D,Cuervo AM, Nixon RA (2010) Lysosomal proteolysis and autophagy re- 
quire presenilin 1 and are disrupted by Alzheimer-related PS1 mutations. Cell 141:1146-1158.

Lee JH, McBrayer MK, Wolfe DM, Haslett LJ, Kumar A, Sato Y, Lie PP, Mohan P, Coffey EE, Kompella U, Mitchell CH, Lloyd-Evans E, Nixon RA (2015) Presenilin 1 maintains lysosomal $\mathrm{Ca}(2+)$ homeostasis via TRPML1 by regulating vATPase-mediated lysosome acidification. Cell Rep 12:1430-1444.

Lee JH, Rao MV, Yang DS, Stavrides P, Im E, Pensalfini A, Huo C, Sarkar P, Yoshimori T, Nixon RA (2019) Transgenic expression of a ratiometric autophagy probe specifically in neurons enables the interrogation of brain autophagy in vivo. Autophagy 15:543-557.

Letourneau A, Santoni FA, Bonilla X, Sailani MR, Gonzalez D, Kind J, Chevalier C, Thurman R, Sandstrom RS, Hibaoui Y, Garieri M, Popadin K, Falconnet E, Gagnebin M, Gehrig C, Vannier A, Guipponi M, Farinelli L, Robyr D, Migliavacca E, et al. (2014) Domains of genome-wide gene expression dysregulation in Down's syndrome. Nature 508:345-350.

Liao G, Yao Y, Liu J, Yu Z, Cheung S, Xie A, Liang X, Bi X (2007) Cholesterol accumulation is associated with lysosomal dysfunction and autophagic stress in $\mathrm{Npcl}^{-1-}$ mouse brain. J Pathol 171:962-975.

Lie PP, Nixon RA (2019) Lysosome trafficking and signaling in health and neurodegenerative diseases. Neurobiol Dis 122:94-105.

Linebaugh BE, Sameni M, Day NA, Sloane BF, Keppler D (1999) Exocytosis of active cathepsin B enzyme activity at $\mathrm{pH} 7.0$, inhibition and molecular mass. Eur J Biochem 264:100-109.

Macías-Vidal J, Guerrero-Hernández M, Estanyol JM, Aguado C, Knecht E, Coll MJ, Bachs O (2016) Identification of lysosomal Npcl-binding proteins: cathepsin D activity is regulated by NPC1. Proteomics 16 : $150-158$.

Majumdar A, Cruz D, Asamoah N, Buxbaum A, Sohar I, Lobel P, Maxfield FR (2007) Activation of microglia acidifies lysosomes and leads to degradation of Alzheimer amyloid fibrils. Mol Biol Cell 18:1490-1496.

Mamo A, Jules F, Dumaresq-Doiron K, Costantino S, Lefrancois S (2012) The role of ceroid lipofuscinosis neuronal protein 5 (CLN5) in endosomal sorting. Mol Cell Biol 32:1855-1866.

Marks N, Berg MJ (1987) Rat brain cathepsin L: characterization and differentiation from cathepsin B utilizing opioid peptides. Arch Biochem Biophys 259:131-143.

Martina JA, Puertollano R (2017) TFEB and TFE3: the art of multi-tasking under stress conditions. Transcription 8:48-54.

Martina JA, Diab HI, Lishu L, Jeong AL, Patange S, Raben N, Puertollano R (2014) The nutrient-responsive transcription factor TFE3 promotes autophagy, lysosomal biogenesis, and clearance of cellular debris. Sci Signal 7:ra9.

Martina JA, Diab HI, Brady OA, Puertollano R (2016) TFEB and TFE3 are novel components of the integrated stress response. EMBO J 35: $479-495$.

Martín-Maestro P, Gargini R, A Sproul A, García E, Antón LC, Noggle S, Arancio O, Avila J, García-Escudero V (2017) Mitophagy failure in fibroblasts and iPSC-derived neurons of Alzheimer's disease-associated presenilin 1 mutation. Front Mol Neurosci 10:291.

Mathews PM, Jiang Y, Schmidt SD, Grbovic OM, Mercken M, Nixon RA (2002) Calpain activity regulates the cell surface distribution of amyloid precursor protein. inhibition of calpains enhances endosomal generation of beta-cleaved C-terminal APP fragments. J Biol Chem 277:3641536424.

Mindell JA (2012) Lysosomal acidification mechanisms. Annu Rev Physiol 74:69-86.

Mondragón-Rodríguez S, Perry G, Luna-Muñoz J, Acevedo-Aquino MC, Williams S (2014) Phosphorylation of tau protein at sites Ser(396404) is one of the earliest events in Alzheimer's disease and Down syndrome. Neuropathol Appl Neurobiol 40:121-135.

Mortazavi A, Williams BA, McCue K, Schaeffer L, Wold B (2008) Mapping and quantifying mammalian transcriptomes by RNA-seq. Nat Methods 5:621-628.

Nixon RA (2013) The role of autophagy in neurodegenerative disease. Nat Med 19:983-997.

Nixon RA (2017) Amyloid precursor protein and endosomal-lysosomal dysfunction in Alzheimer's disease: inseparable partners in a multifactorial disease. FASEB J 31:2729-2743.

Nixon RA, Cataldo AM (1993) The lysosomal system in neuronal cell death: a review. Ann N Y Acad Sci 679:87-109.
Nixon RA, Yang DS (2012) Autophagy and neuronal cell death in neurological disorders. Cold Spring Harb Perspect Biol 4:a008839.

Nixon RA, Yang DS, Lee JH (2008) Neurodegenerative lysosomal disorders: a continuum from development to late age. Autophagy 4:590-599.

Pal R, Bajaj L, Sharma J, Palmieri M, Di Ronza A, Lotfi P, Chaudhury A, Neilson J, Sardiello M, Rodney GG (2016) NADPH oxidase promotes parkinsonian phenotypes by impairing autophagic flux in an mTORC1independent fashion in a cellular model of Parkinson's disease. Sci Rep 6:22866.

Peake KB, Vance JE (2012) Normalization of cholesterol homeostasis by 2-hydroxypropyl-beta-cyclodextrin in neurons and glia from NiemannPick C1 (NPC1)-deficient mice. J Biol Chem 287:9290-9298.

Pera M, Alcolea D, Sánchez-Valle R, Guardia-Laguarta C, Colom-Cadena M, Badiola N, Suárez-Calvet M, Lladó A, Barrera-Ocampo AA, SepulvedaFalla D, Blesa R, Molinuevo JL, Clarimón J, Ferrer I, Gelpi E, Lleó A (2013) Distinct patterns of APP processing in the CNS in autosomaldominant and sporadic Alzheimer disease. Acta Neuropathol 125: 201-213.

Perez-Gonzalez R, Gauthier SA, Kumar A, Levy E (2012) The exosome secretory pathway transports amyloid precursor protein carboxyl-terminal fragments from the cell into the brain extracellular space. J Biol Chem 287:43108-43115.

Perluigi M, Butterfield DA (2012) Oxidative stress and Down syndrome: a route toward Alzheimer-like dementia. Curr Gerontol Geriatr Res 2012: 724904.

Perluigi M, Pupo G, Tramutola A, Cini C, Coccia R, Barone E, Head E, Butterfield DA, Di Domenico F (2014) Neuropathological role of PI3K/ Akt/mTOR axis in Down syndrome brain. Biochim Biophys Acta 1842: $1144-1153$

Piccoli C, Izzo A, Scrima R, Bonfiglio F, Manco R, Negri R, Quarato G, Cela O, Ripoli M, Prisco M, Gentile F, Calì G, Pinton P, Conti A, Nitsch L, Capitanio N (2013) Chronic pro-oxidative state and mitochondrial dysfunctions are more pronounced in fibroblasts from Down syndrome foeti with congenital heart defects. Hum Mol Genet 22:1218-1232.

Pullen N, Dennis PB, Andjelkovic M, Dufner A, Kozma SC, Hemmings BA, Thomas G (1998) Phosphorylation and activation of p70s6k by PDK1. Science 279:707-710.

Ritchie ME, Phipson B, Wu D, Hu Y, Law CW, Shi W, Smyth GK (2015) limma powers differential expression analyses for RNA-sequencing and microarray studies. Nucleic Acids Res 43:e47.

Robinson MD, McCarthy DJ, Smyth GK (2010) edgeR: a bioconductor package for differential expression analysis of digital gene expression data. Bioinformatics 26:139-140.

Schwagerl AL, Mohan PS, Cataldo AM, Vonsattel JP, Kowall NW, Nixon RA (1995) Elevated levels of the endosomal-lysosomal proteinase cathepsin D in cerebrospinal fluid in Alzheimer disease. J Neurochem 64:443-446.

Sevlever D, Jiang P, Yen SH (2008) Cathepsin D is the main lysosomal enzyme involved in the degradation of alpha-synuclein and generation of its carboxy-terminally truncated species. Biochemistry 47:96789687.

Siintola E, Partanen S, Strömme P, Haapanen A, Haltia M, Maehlen J, Lehesjoki AE, Tyynelä J (2006) Cathepsin D deficiency underlies congenital human neuronal ceroid-lipofuscinosis. Brain 129:1438-1445.

Simón AM, Schiapparelli L, Salazar-Colocho P, Cuadrado-Tejedor M, Escribano L, López de Maturana R, Del Río J, Pérez-Mediavilla A, Frechilla D (2009) Overexpression of wild-type human APP in mice causes cognitive deficits and pathological features unrelated to abeta levels. Neurobiol Dis 33:369-378.

Stoka V, Turk V, Turk B (2016) Lysosomal cathepsins and their regulation in aging and neurodegeneration. Ageing Res Rev 32:22-37.

Sullivan KD, Lewis HC, Hill AA, Pandey A, Jackson LP, Cabral JM, Smith KP, Liggett LA, Gomez EB, Galbraith MD, DeGregori J, Espinosa JM (2016) Trisomy 21 consistently activates the interferon response. eLife 5:e16220.

Tamayev R, Matsuda S, Giliberto L, Arancio O, D’Adamio L (2011) APP heterozygosity averts memory deficit in knockin mice expressing the Danish dementia BRI2 mutant. EMBO J 30:2501-2509.

Tatti M, Motta M, Di Bartolomeo S, Cianfanelli V, Salvioli R (2013) Cathepsin-mediated regulation of autophagy in saposin C deficiency. Autophagy 9:241-243.

Tyynelä J, Sohar I, Sleat DE, Gin RM, Donnelly RJ, Baumann M, Haltia M, 
Lobel P (2000) A mutation in the ovine cathepsin D gene causes a congenital lysosomal storage disease with profound neurodegeneration. EMBO J 19:2786-2792.

Vassar R, Bennett BD, Babu-Khan S, Kahn S, Mendiaz EA, Denis P, Teplow DB, Ross S, Amarante P, Loeloff R, Luo Y, Fisher S, Fuller J, Edenson S, Lile J, Jarosinski MA, Biere AL, Curran E, Burgess T, Louis JC, et al. (1999) Beta-secretase cleavage of Alzheimer's amyloid precursor protein by the transmembrane aspartic protease BACE. Science 286:735-741.

Vidoni C, Follo C, Savino M, Melone MA, Isidoro C (2016) The role of cathepsin D in the pathogenesis of human neurodegenerative disorders. Med Res Rev 36:845-870.

Wendeler M, Sandhoff K (2009) Hexosaminidase assays. Glycoconj J 26:945-952.

Wolfe DM, Lee JH, Kumar A, Lee S, Orenstein SJ, Nixon RA (2013) Autophagy failure in Alzheimer's disease and the role of defective lysosomal acidification. Eur J Neurosci 37:1949-1961.

Xue X, Wang LR, Sato Y, Jiang Y, Berg M, Yang DS, Nixon RA, Liang XJ
(2014) Single-walled carbon nanotubes alleviate autophagic/lysosomal defects in primary glia from a mouse model of Alzheimer's disease. Nano Lett 14:5110-5117.

Yang DS, Stavrides P, Saito M, Kumar A, Rodriguez-Navarro JA, Pawlik M, Huo C, Walkley SU, Saito M, Cuervo AM, Nixon RA (2014) Defective macroautophagic turnover of brain lipids in the TgCRND8 Alzheimer mouse model: prevention by correcting lysosomal proteolytic deficits. Brain 137:3300-3318.

Zhang S, Eitan E, Mattson MP (2017) Early involvement of lysosome dysfunction in the degeneration of cerebral cortical neurons caused by the lipid peroxidation product 4-hydroxynonenal. J Neurochem 140:941954.

Zhou C, Zhong W, Zhou J, Sheng F, Fang Z, Wei Y, Chen Y, Deng X, Xia B, Lin J (2012) Monitoring autophagic flux by an improved tandem fluorescent-tagged LC3 (mTagRFP-mWasabi-LC3) reveals that highdose rapamycin impairs autophagic flux in cancer cells. Autophagy $8: 1215-1226$. 